\title{
Modeling and Analysis of Coupling Performance of Dynamic Stiffness Models for a Novel Combined Radial-Axial Hybrid Magnetic Bearing
}

\author{
Bangcheng Han ${ }^{1,2,3}$ and Shiqiang Zheng ${ }^{1,2,3}$ \\ ${ }^{1}$ Fundamental Sciency on Novel Inertial Instrument \& Navitation System Technoloty Laboratory, \\ Beijing 100191, China \\ ${ }^{2}$ Science and Technology on Inertial Laboratory, Beijing 100191, China \\ ${ }^{3}$ School of Instrument Science and Opto-electronics Engineering, Beihang University, Beijing 100191, China
}

Correspondence should be addressed to Bangcheng Han; hanbangcheng@buaa.edu.cn

Received 27 June 2013; Accepted 18 November 2013; Published 12 January 2014

Academic Editor: Paulo Batista Gonçalves

Copyright $\odot 2014$ B. Han and S. Zheng. This is an open access article distributed under the Creative Commons Attribution License, which permits unrestricted use, distribution, and reproduction in any medium, provided the original work is properly cited.

\begin{abstract}
The combined radial-axial magnetic bearing (CRAMB) with permanent magnet creating bias flux can reduce the size, cost, and mass and save energy of the magnetic bearing. The CRAMB have three-degree-of-freedom control ability, so its structure and magnetic circuits are more complicated compared to those of the axial magnetic bearing (AMB) or radial magnetic bearing (RMB). And the eddy currents have a fundamental impact on the dynamic performance of the CRAMB. The dynamic stiffness model and its cross coupling problems between different degrees of freedom affected for the CRAMB are proposed in this paper. The dynamic current stiffness and the dynamic displacement stiffness models of the CRAMB are deduced by using the method of equivalent magnetic circuit including eddy current effect, but the dynamic current stiffness of the RMB unit is approximately equal to its static current stiffness. The analytical results of an example show that the bandwidth of the dynamic current stiffness of the AMB unit and the dynamic displacement stiffness of the CRAMB is affected by the time-varying control currents or air gap, respectively. And the dynamic current stiffness and the dynamic displacement stiffness between the AMB unit and the RMB unit are decoupled due to few coupling coefficients.
\end{abstract}

\section{Introduction}

Most of 5-axis active magnetic bearing systems (MBSs) are usually composed of two radial magnetic bearing (RMB) units and one axial magnetic bearing (AMB) unit [1-5]. These magnetic bearing systems are the easiest way to be produced, but they are also tending to bulky, high power and high cost. In order to reduce the size, cost, and save energy and increase the high-power density of the MBS, which is important to reduce the number of the units by means of furthermore combination the AMB and RMB. A combined radial-axial magnetic bearing (CRAMB) which is named as 3 -axis magnetic bearing $(\mathrm{MB})$ is designed for use in an ultra-high-speed machine [6]. The magnetic forces and coupling problems of a combined $\mathrm{AMB}$ and $\mathrm{RMB}$ are analyzed [7]. The integrated AMB and RMB with conical rotor are designed and analyzed $[8,9]$, and one downside of the integrated bearings is a strong coupling problem between the radial and axial degrees of freedom. An AC-DC 3-DOF hybrid magnetic bearing is proposed and designed [10]. Structure and control method of an AC-DC 3-DOF hybrid magnetic bearing is introduced in the literature [11-14]. A 3 -DOF axial hybrid magnetic bearing [15] is proposed, but the structure and processing technic are very complicated, and its rotational power loss will be large at high speed. The structure of a 3-DOF magnetic bearing without large thrust 
disk rotor is introduced and designed [16]. An integrated radial-axial magnetic bearing without axial disk is presented in the literature, and its static performance is analyzed by using 3-D FEM. The static mathematical model of a radialaxial magnetic bearing is introduced in the literatures $[17,18]$.

Most literatures mentioned above described the structure, design, analysis, and control methods of the CRAMBs, which are mainly consider the static mathematical model without including the eddy-current effects. But few literatures on the dynamic stiffness modeling and coupling problems of CRAMB with permanent magnet bias are described when considering the dynamic characteristics affected by the eddy currents caused by time-varying air gap and control currents. Some parts of the CRAMB are very difficult to be split into laminated which can reduce the eddy-current loss, then the eddy currents will result in magnitude reduction and phase lag of radial and axial magnetic force and make the core hotter. That is to say, the eddy current has a serious impact on the dynamic performances of the CRAMB.

Due to the coupled magnetic, electrical, and mechanical domains, design and analysis of CRAMB are very difficult. In particular, its dynamic characteristics are affected by the coupled domains mentioned above. As a result, to predict the dynamic operating characteristics is necessary to avoid costly trials. A few simple dynamic models including eddy currents are described for magnetic actuators [19-25]. The finite element method (FEM) is also used to analyze the eddy-current effects on the active thrust MBs. The electromechanical performance of magnetic actuators is analyzed using a coupled structural and electromagnetic FEM [26, 27]. The dynamic characteristics of $\mathrm{MB}$ based on field-circuit coupled method are proposed [28]. The FEM is used to analyze the operating characteristics of the electromagnet with permanent magnets [29]. The dynamic stiffness models of active thrust magnetic bearing are also analyzed by FEM and analytical method [30, 31]. The eddy current loss in surface layer of a laminated core [32] and a solid core [33] for radial $\mathrm{MB}$ is analyzed. And the experimental methods are used to investigate the eddy-current effects. The force/current relationship of a solid thrust $\mathrm{MB}$ is tested by Allaire et al. [34]. DeWeese et al. investigated different rotor and stator configurations to find the one with minimal eddy currents [35]. The limitations on the closed-loop performance of active thrust MB affected by the eddy currents are investigated [36].

The emphases of dynamic stiffness mentioned above are the active thrust $\mathrm{MB}$ which has one degree of freedom (DOF), and the structure and magnetic flux path are easy to design and analyze. The structure and magnetic circuits of the CRAMB are more complicated compared to those of the thrust $\mathrm{MB}$ or radial $\mathrm{MB}$, and the cross-coupling problems between different DOFs may be produced. But few literatures on dynamic characteristics and the coupling problems of the CRAMB are published. So, it would have higher research value to investigate the accurate dynamic factor model and the coupling problems including eddy currents rather than the static mathematic model. The dynamic stiffness models and the dynamic coupling models including eddy-current effects for CRAMB with permanent magnet bias are presented and derived analytically by using equivalent magnetic

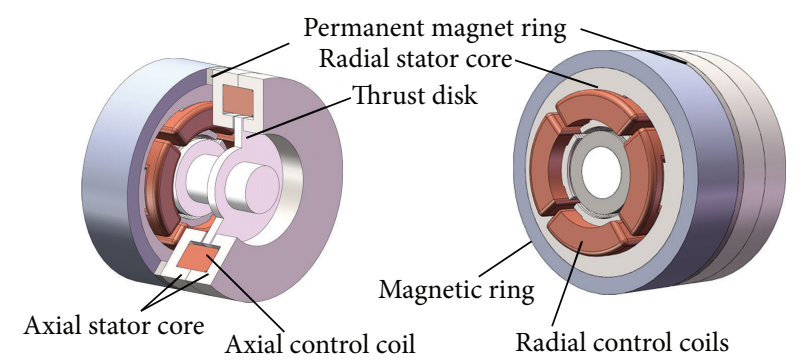

FIGURE 1: Configuration of the CRAMB with permanent magnet ring.

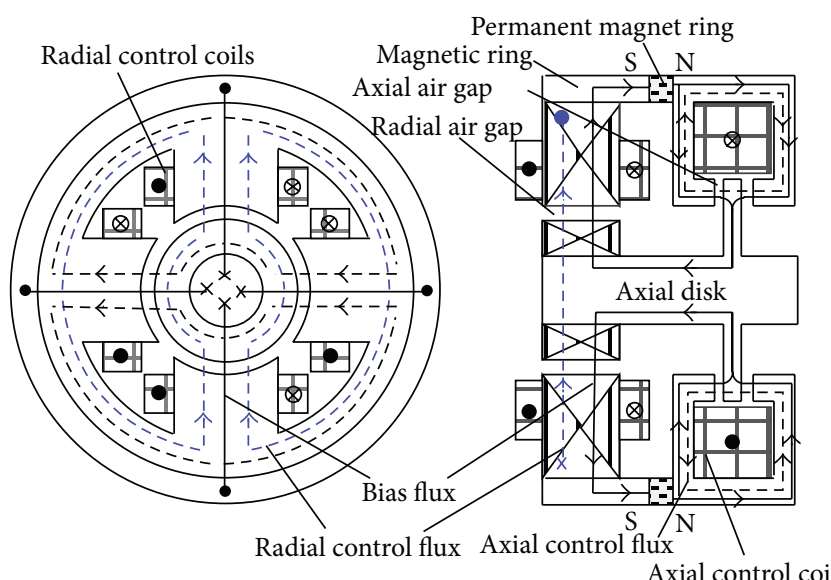

FIGURE 2: The magnetic circuits of the combined radial-axial magnetic bearing with permanent magnet ring.

circuit method in this paper. The dynamic current stiffness models and the dynamic displacement stiffness models of the $\mathrm{RMB}$ unit and $\mathrm{AMB}$ unit are given. And the dynamic coupling models between axial and radial bearing units are also given. An example is also given in this paper.

\section{Analysis Model and Method}

2.1. Analysis Model. Figure 1 shows the configuration of the CRAMB which combines the radial and axial magnetic bearing unit. The axially magnetized permanent magnet ring (PMR) is used to produce bias flux for both the RMB and the AMB unit. The laminations are used only for radial stator and rotor core, and the other parts are made of solid material. Smaller outside diameter of the rotor thrust disk is used. Therefor the lower rotational drag, the lower stresses, and the compact structure are attained. The magnetic ring is used to eliminate the saturation of the magnetic circuit for the stator core of the RMB unit. The bias flux and the control flux paths of the RMB and AMB unit are depicted in Figure 2. The solid line indicates the bias flux paths generated by the PMR and the dotted line denotes the control flux paths generated by the control current of the AMB and the RMB unit. As can be seen, their control flux produced by the control current in coils will pass through air gap of the RAM and the AMB rather than the $\mathrm{PMR}$, and therefore small control currents are 


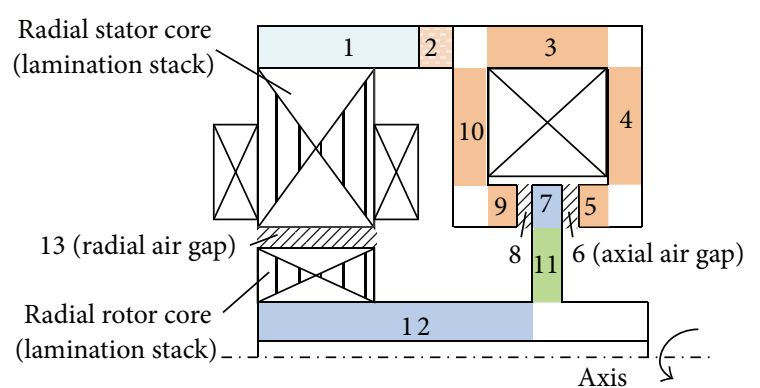

Figure 3: Division of the geometry of the CRAMB: 13 elements simply divided.

enough since they do not have to compensate for the high magnetic reluctance of the PMR. The control flux has to be superimposed by the bias flux in air gap for producing the axial and radial magnetic force.

The radial and axial magnetic bearing force and flux can be derived conveniently with the static magnetic circuit model without consideration of the eddy-current effect. However, the eddy currents caused by the time-varying air gap and the control currents will affect the dynamic characteristics of the CRAMB system. Based on an approximate analysis method [22] considering the eddy-current effect inside a nonlaminated electromagnetic actuator, the CRAMB geometry is divided into thirteen elements as shown in Figure 3. The four elements of the air gap between rotor and stator of the RMB are named as element 13 . The eddycurrent loss can be reduced by using laminated stator core and rotor core of the RMB unit in CRAMB. According to the equivalent magnetic circuit models of the CRAMB, the effective reluctances are separated into two parts: one is the static magnetic reluctance of element, and the other one is the dynamic magnetic reluctance which is a half-order term related to frequency.

The elements 1-5, 7, and 9-12 can be divided in the same way as in Sun et al.'s models [30] and Zhu et al's models [23]. The PMR is used for element 2 which is used to provide bias flux and can also be simplified in the same way. The elements $1,2,11$, and 12 are located in the bias flux path. Therefore, the eddy-current effect should be considered in mathematical model. The simplified effective reluctance of each element can be used to design, analyze, and control purpose. The simplified calculation of the effective magnetic reluctances for these elements is given as follow:

$$
R_{1}=R_{1}^{0}+R_{1}^{i}=\frac{h_{1}}{\pi \mu_{0} \mu_{r}\left(r_{6}^{2}-r_{5}^{2}\right)}+\frac{h_{1}}{2 \pi r_{5}} \sqrt{\frac{j \omega \sigma_{1}}{\mu_{0} \mu_{r}}}
$$

where $R_{1}^{0}=h_{1} / \pi \mu_{0} \mu_{r}\left(r_{6}^{2}-r_{5}^{2}\right), R_{1}^{i}=\left(h_{1} / 2 \pi r_{5}\right) \sqrt{j \omega \sigma_{1} / \mu_{0} \mu_{r}}$

$$
R_{2}=R_{2}^{0}+R_{2}^{i}=\frac{h_{2}}{\pi \mu_{0} \mu_{r}\left(r_{6}^{2}-r_{5}^{2}\right)}+\frac{h_{2}}{2 \pi r_{5}} \sqrt{\frac{j \omega \sigma_{2}}{\mu_{0} \mu_{r}}}
$$

where $R_{2}^{0}=h_{2} / \pi \mu_{0} \mu_{r}\left(r_{6}^{2}-r_{5}^{2}\right), R_{2}^{i}=\left(h_{2} / 2 \pi r_{5}\right) \sqrt{j \omega \sigma_{2} / \mu_{0} \mu_{r}}$

$$
R_{3}=R_{3}^{0}+R_{3}^{i}=\frac{h_{4}}{\pi \mu_{0} \mu_{r}\left(r_{6}^{2}-r_{5}^{2}\right)}+\frac{h_{4}}{2 \pi r_{5}} \sqrt{\frac{j \omega \sigma_{1}}{\mu_{0} \mu_{r}}},
$$

where $R_{3}^{0}=h_{4} / \pi \mu_{0} \mu_{r}\left(r_{6}^{2}-r_{5}^{2}\right), R_{3}^{i}=\left(h_{4} / 2 \pi r_{5}\right) \sqrt{j \omega \sigma_{1} / \mu_{0} \mu_{r}}$

$$
R_{4}=R_{4}^{0}+R_{4}^{i}=\frac{\ln \left(r_{6} / r_{4}\right)}{2 \pi \mu_{0} \mu_{r} h_{5}}+\frac{\ln \left(r_{6} / r_{4}\right)}{2 \pi} \sqrt{\frac{j \omega \sigma_{1}}{\mu_{0} \mu_{r}}}
$$

where $R_{4}^{0}=\ln \left(r_{6} / r_{4}\right) / 2 \pi \mu_{0} \mu_{r} h_{5}, R_{4}^{i}=\left(\ln \left(r_{6} / r_{4}\right) /\right.$ $2 \pi) \sqrt{j \omega \sigma_{1} / \mu_{0} \mu_{r}}$

$$
R_{5}=R_{5}^{0}+R_{5}^{i}=\frac{h_{6}}{\pi \mu_{0} \mu_{r}\left(r_{4}^{2}-r_{3}^{2}\right)}+\frac{h_{6}}{2 \pi r_{3}} \sqrt{\frac{j \omega \sigma_{1}}{\mu_{0} \mu_{r}}},
$$

where $R_{5}^{0}=h_{6} / \pi \mu_{0} \mu_{r}\left(r_{4}^{2}-r_{3}^{2}\right), R_{5}^{i}=\left(h_{6} / 2 \pi r_{3}\right) \sqrt{j \omega \sigma_{1} / \mu_{0} \mu_{r}}$

$$
\begin{gathered}
R_{z 1}=R_{6}=\frac{s_{0}+z}{\pi \mu_{0}\left(r_{4}^{2}-r_{3}^{2}\right)}, \\
R_{z 10}=R_{6}^{0}=\frac{s_{0}}{\pi \mu_{0}\left(r_{4}^{2}-r_{3}^{2}\right)}, \quad z=0, \\
R_{7}=R_{7}^{0}+R_{7}^{i}=\frac{\ln \left(r_{4} / r_{3}\right)}{2 \pi \mu_{0} \mu_{r} h_{7}}+\frac{\ln \left(r_{4} / r_{3}\right)}{2 \pi} \sqrt{\frac{j \omega \sigma_{1}}{\mu_{0} \mu_{r}}}
\end{gathered}
$$

where $R_{7}^{0}=\ln \left(r_{4} / r_{3}\right) / 2 \pi \mu_{0} \mu_{r} h_{7}, R_{7}^{i}=\left(\ln \left(r_{4} / r_{3}\right) /\right.$ $2 \pi) \sqrt{j \omega \sigma_{1} / \mu_{0} \mu_{r}}$

$$
\begin{gathered}
R_{z 2}=R_{8}=\frac{s_{0}-z}{\pi \mu_{0}\left(r_{4}^{2}-r_{3}^{2}\right)}, \\
R_{z 0}=R_{z 20}=R_{8}^{0}=R_{z 10}=\frac{s_{0}}{\pi \mu_{0}\left(r_{4}^{2}-r_{3}^{2}\right)}, \quad z=0, \\
R_{9}=R_{9}^{0}+R_{9}^{i}=R_{5}=R_{5}^{0}+R_{5}^{i},
\end{gathered}
$$

where $R_{9}^{0}=h_{6} / \pi \mu_{0} \mu_{r}\left(r_{4}^{2}-r_{3}^{2}\right), R_{9}^{i}=\left(h_{6} / 2 \pi r_{3}\right) \sqrt{j \omega \sigma_{1} / \mu_{0} \mu_{r}}$

$$
R_{10}=R_{10}^{0}+R_{10}^{i}=R_{4}=R_{4}^{0}+R_{4}^{i} \text {, }
$$

where $R_{10}^{0}=\ln \left(r_{6} / r_{4}\right) / 2 \pi \mu_{0} \mu_{r} h_{5}, R_{10}^{i}=\left(\ln \left(r_{6} / r_{4}\right) /\right.$ $2 \pi) \sqrt{j \omega \sigma_{1} / \mu_{0} \mu_{r}}$

$$
R_{11}=R_{11}^{0}+R_{11}^{i}=\frac{\ln \left(r_{3} / r_{1}\right)}{2 \pi \mu_{0} \mu_{r} h_{7}}+\frac{\ln \left(r_{3} / r_{1}\right)}{2 \pi} \sqrt{\frac{j \omega \sigma_{1}}{\mu_{0} \mu_{r}}},
$$

where $R_{11}^{0}=\ln \left(r_{3} / r_{1}\right) / 2 \pi \mu_{0} \mu_{r} h_{7}, R_{11}^{i}=\left(\ln \left(r_{3} / r_{1}\right) /\right.$ $2 \pi) \sqrt{j \omega \sigma_{1} / \mu_{0} \mu_{r}}$

$$
R_{12}=R_{12}^{0}+R_{12}^{i}=\frac{h_{9}}{\pi \mu_{0} \mu_{r}\left(r_{1}^{2}-r_{8}^{2}\right)}+\frac{h_{9}}{2 \pi r_{8}} \sqrt{\frac{j \omega \sigma_{1}}{\mu_{0} \mu_{r}}},
$$

where $R_{12}^{0}=h_{9} / \pi \mu_{0} \mu_{r}\left(r_{1}^{2}-r_{8}^{2}\right), R_{12}^{i}=\left(h_{9} / 2 \pi r_{8}\right) \sqrt{j \omega \sigma_{1} / \mu_{0} \mu_{r}}$

$$
R_{13}=R_{13}^{0}=\frac{360\left(r_{3}-r_{2}\right)}{\pi \mu_{0} h_{10}\left(r_{3}+r_{2}\right)},
$$

where $R_{j}^{0}$ is the static magnetic reluctance (the first term in $R_{j}$ for element $j$ ) and $R_{j}^{i}$ is the eddy-current magnetic reluctance (the second term in $R_{j}$ for element $j$ ) with $j=1,2, \ldots, 13$, 


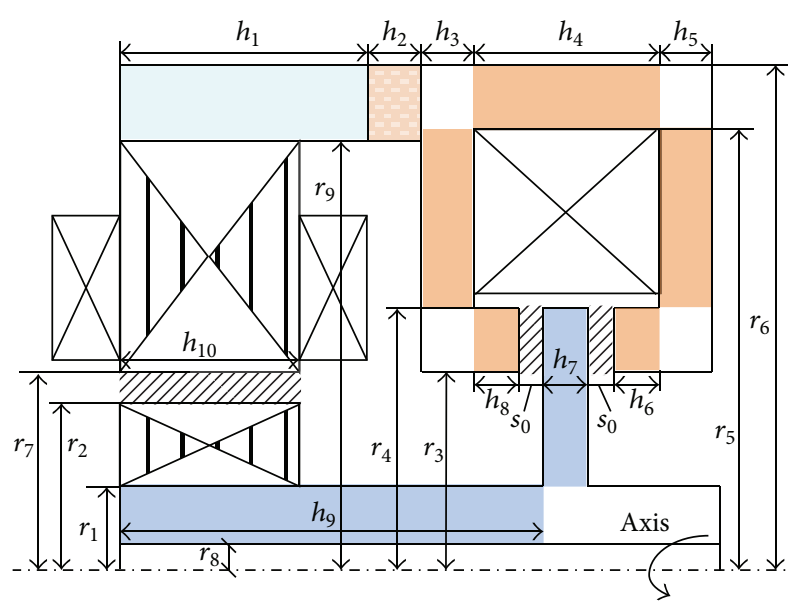

Figure 4: The dimension of the CRAMB.

and the parameters and their dimensions are given in Figure 4 and Table $1 . R_{13}$ is the magnetic reluctance of the radial air gap. $R_{6}$ and $R_{8}$ are the magnetic reluctances of the axial air gap. The equivalent magnetic circuits including the bias magnetic circuit and the control magnetic circuits of the CRAMB without the leakage flux are shown in Figure 5. We focus on the investigation of the eddy-current effects, and the equivalent magnetic reluctances for the leakage flux paths would be included in the future model.

\subsection{Dynamic Current Stiffness Model for the AMB Unit of} $C R A M B$. It is assumed that the CRAMB system is linear, and the AMB unit of the CRAMB excited a sinusoidal varying ac current $i_{z}=I_{z} \sin (\omega t)$ (where the amplitude, $I_{z}$, is very small). When the thrust disk located its center position, the length of air gap (the element 6,8 ) is $s_{0}$.

The control flux $\phi_{z i}$ produced by a sinusoidal varying ac current $i_{z}$ in the axial air gap of AMB unit and the bias flux $\phi_{z m 0}$ in the axial air gap of AMB unit produced by the PMR, the control flux in the left air gap (element 8) will add to the bias flux, and will subtract from the bias flux in the right air gap (element 6) as shown in Figure 3. The total flux, $\phi_{z s u m i}(i=1,2)$, in the left and the right air gap of AMB unit is given as

$$
\begin{aligned}
& \phi_{z \text { sum } 1}=\phi_{z m 0}+\phi_{z i}, \\
& \phi_{z \text { sum } 2}=\phi_{z m 0}-\phi_{z i},
\end{aligned}
$$

where the static bias flux in the axial air gap of AMB unit is calculated as

$$
\begin{array}{r}
\phi_{z m}=F_{m}\left(R_{1}^{0}+R_{2}^{0}+R_{7}^{0}+R_{11}^{0}+R_{12}^{0}+\frac{R_{13}}{4}\right. \\
\left.+\frac{1}{1 / \sum_{k=3}^{6} R_{k}^{0}+1 / \sum_{j=8}^{10} R_{j}^{0}}\right)^{-1} .
\end{array}
$$

\begin{tabular}{|c|c|c|}
\hline Parameters & Description & Value \\
\hline$r_{1}$ & Inner radius of the $\mathrm{RMB}$ rotor, $(\mathrm{mm})$ & 25 \\
\hline$r_{2}$ & Outer radius of the $\mathrm{RMB}$ rotor, $(\mathrm{mm})$ & 30 \\
\hline$r_{7}$ & Inner radius of the $\mathrm{RMB}$ stator, $(\mathrm{mm})$ & 30.5 \\
\hline$A_{r}$ & Radial pole shoe area, $\left(\mathrm{mm}^{2}\right)$ & 1036 \\
\hline$N_{r}$ & $\begin{array}{l}\text { The number of winding turns in coil of } \\
\text { RMB }\end{array}$ & 220 \\
\hline$r_{9}$ & Outer radius of the $\mathrm{RMB}$ stator, $(\mathrm{mm})$ & 60 \\
\hline$r_{6}$ & Outer radius of the yoke, $(\mathrm{mm})$ & 70 \\
\hline$r_{3}$ & $\begin{array}{l}\text { Inner radius of the axial pole shoe, } \\
(\mathrm{mm})\end{array}$ & 31 \\
\hline$r_{4}$ & $\begin{array}{l}\text { Outer radius of the axial pole shoe, } \\
(\mathrm{mm})\end{array}$ & 34 \\
\hline$r_{5}$ & Inner radius of the yoke, $(\mathrm{mm})$ & 62 \\
\hline$r_{8}$ & Inner radius of the RMB rotor, $(\mathrm{mm})$ & 10 \\
\hline$h_{1}$ & $\begin{array}{l}\text { Length of the stator return ring of } \\
\mathrm{RMB},(\mathrm{mm})\end{array}$ & 31 \\
\hline$h_{2}$ & $\begin{array}{l}\text { Thickness of the permanent ring, } \\
(\mathrm{mm})\end{array}$ & 10 \\
\hline$h_{3}$ & Thickness of the element $10,(\mathrm{~mm})$ & 8 \\
\hline$h_{4}$ & Thickness of the element $3,(\mathrm{~mm})$ & 24 \\
\hline$h_{5}$ & Thickness of the element $4,(\mathrm{~mm})$ & 8 \\
\hline$h_{6}$ & Thickness of the element $5,(\mathrm{~mm})$ & 8 \\
\hline$h_{7}$ & Thickness of the thrust plane, $(\mathrm{mm})$ & 7 \\
\hline$h_{8}$ & Thickness of the element $9,(\mathrm{~mm})$ & 8 \\
\hline$h_{9}$ & Thickness of the element $12,(\mathrm{~mm})$ & 8 \\
\hline$s_{0}$ & radial and axial air gap, (mm) & 0.5 \\
\hline$N_{z}$ & $\begin{array}{l}\text { The number of winding turns in coil of } \\
\text { AMB }\end{array}$ & 120 \\
\hline$m$ & The mass of the rotor, $(\mathrm{kg})$ & 7.2 \\
\hline$\sigma_{1}$ & $\begin{array}{l}\text { The conductivity of yoke and thrust } \\
\text { disk, }(\mathrm{S} / \mathrm{m})\end{array}$ & $8 \times 10^{6}$ \\
\hline$\mu_{0}$ & Permeability of free space, $(\mathrm{H} / \mathrm{m})$ & $4 \pi \times 10^{-7}$ \\
\hline$\mu_{r}$ & $\begin{array}{l}\text { Relative permeability of the permanent } \\
\text { magnet }\end{array}$ & 1.082 \\
\hline$\sigma_{2}$ & Resistivity of the magnet ring, $(\Omega \cdot \mathrm{m})$ & $0.9 E-6$ \\
\hline
\end{tabular}

The permanent magnet material of the PMR is Nd-Fe$\mathrm{B}$, its magnetomotive force is $F_{m}=H_{c} h_{2}$, and $H_{c}$ is the
TABLE 1: Parameters of The CRAMB.

coercive force of the PMR; $h_{2}$ is thickness of the PMR. The permeability of the magnetic ring and the thrust disk is compared to that of the air and the PMB, so (13) can be simplified as

$$
\phi_{z m} \approx \frac{F_{m}}{R_{2}^{0}+R_{13} / 4+R_{z 0} / 2} .
$$

And the static bias flux in the air gap of the AMB can be calculated as

$$
\phi_{z m 0}=\phi_{z 1}^{0}=\phi_{z 2}^{0}=\frac{\phi_{z m}}{2}=\frac{F_{m}}{2 R_{2}^{0}+R_{13} / 2+R_{z 0}} .
$$




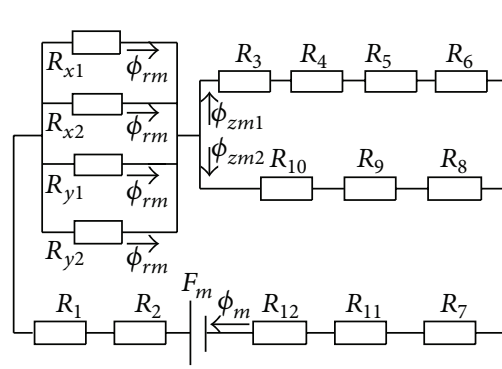

(a)

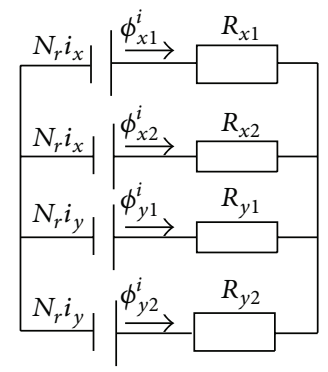

(b)

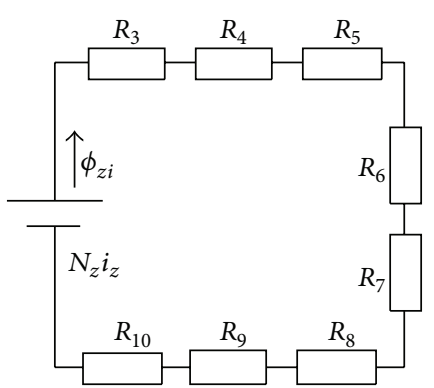

(c)

Figure 5: The equivalent magnetic circuits of the CRAMB. (a) The equivalent magnetic circuit of the bias flux paths. (b) The equivalent magnetic circuit of control flux path of the RMB unit. (c) The equivalent magnetic circuit of control flux path of the AMB unit.

The dynamic flux in the air gap of AMB unit produced by the ac current is calculated as

$$
\begin{aligned}
\phi_{z i} & =\frac{N_{z} I_{z} \sin (\omega t)}{\sum_{k=1}^{10} R_{k}}=\frac{N_{z} I_{z}}{R_{z i}^{0}} \frac{\sin (\omega t)}{1+R_{e}(\omega) / R_{z i}^{0}} \\
& =\frac{N_{z} I_{z} \sin (\omega t)}{R_{z i}^{0}(1+\lambda)},
\end{aligned}
$$

where $R_{z i}^{0}$ is the total static magnetic reluctance of the equivalent magnetic circuit of control flux path for AMB unit, $R_{e}(\omega)$ is the total eddy-current magnetic reluctance of the equivalent magnetic circuit of control flux path for AMB unit, and $\lambda$ is the ratio of the total eddy-current magnetic reluctance to the total static magnetic reluctance $R_{e}(\omega) / R_{z i}^{0}$ :

$$
\begin{gathered}
R_{z i}^{0}=R_{6}^{0}+R_{8}^{0}, \\
R_{e}(\omega)=R_{3}^{i}+R_{4}^{i}+R_{5}^{i}+R_{7}^{i}+R_{9}^{i}+R_{10}^{i} .
\end{gathered}
$$

$R_{e}(\omega)$ is the magnetic reluctance including the eddy current effect, and it will be increased with the addition of frequency of the time-varying air gap and the control currents. The bandwidth will be increased with the addition of the air gap.

The AMB unit of the CRAMB will produce a net restoring force $f_{z i}$ on the thrust disk in $z$-axis direction. Since the net force, $f_{z i}$, is calculated by

$$
f_{z i}=\frac{\phi_{z 1}^{2}}{2 \mu_{0} A_{z}}-\frac{\phi_{z 2}^{2}}{2 \mu_{0} A_{z}}
$$

where the constant $\mu_{0}$ is the permeability of free space, $A_{z}$ is the area of pole face of the AMB unit; substituting (12) into (18) gives

$$
f_{z i}=\frac{\left(\phi_{z m 0}+\phi_{z i}\right)^{2}}{2 \mu_{0} A_{z}}-\frac{\left(\phi_{z m 0}-\phi_{z i}\right)^{2}}{2 \mu_{0} A_{z}}=\frac{2 \phi_{z m 0} \phi_{z i}}{\mu_{0} A_{z}}
$$

The dynamic current stiffness of the AMB unit can be derived as

$$
k_{z i}^{i}=\frac{d f_{z i}}{d i_{z}}=\frac{2 \phi_{z m 0} N_{z}}{\mu_{0} A_{z} R_{z i}^{0}(1+\lambda)}=\frac{k_{z i}^{0}}{1+\lambda},
$$

where

$$
k_{z i}^{0}=\frac{2 \phi_{z m 0} N_{z}}{\mu_{0} A_{z} R_{z i}^{0}}
$$

is the static current stiffness of the AMB unit.

2.3. Dynamic Displacement Stiffness Model for the AMB Unit of CRAMB. When the coil currents in the RMB and the AMB unit are zero, the air gap in the RMB remains stationary, but the air gap in the AMB unit varies sinusoidally about the nominal value $s_{0}$; that is, $z_{1}=s_{0}-\delta \sin (\omega t)$ in left air gap, and $z_{2}=s_{0}+\delta \sin (\omega t)$ in right air gap; then the magnetic reluctance of the air gap will also vary sinusoidally about the nominal value. Thus, the reluctance of the two air gaps in AMB unit includes two parts, one is the static reluctance, $R_{z i}^{0}(i=1,2)$, and the other one is the dynamic reluctance, $R_{z i}^{d}(i=1,2)$. Consider the following:

$$
\begin{aligned}
& R_{z 1}=R_{z 1}^{0}+R_{z 1}^{d}=\frac{s_{0}}{\mu_{0} A_{z}}+\frac{\delta \sin (\omega t)}{\mu_{0} A_{z}}, \\
& R_{z 2}=R_{z 2}^{0}+R_{z 2}^{d}=\frac{s_{0}}{\mu_{0} A_{z}}-\frac{\delta \sin (\omega t)}{\mu_{0} A_{z}},
\end{aligned}
$$

where

$$
\begin{gathered}
R_{z 1}^{0}=R_{z 2}^{0}=\frac{s_{0}}{\mu_{0} A_{z}}, \\
R_{z 1}^{d}=-R_{z 2}^{d}=\frac{\delta \sin (\omega t)}{\mu_{0} A_{z}} .
\end{gathered}
$$

If all the eddy-current reluctances and leakage reluctances are ignored, the total static magnetic reluctance $R_{\text {met }}$ in the bias magnetic circuit is

$$
\begin{aligned}
R_{\mathrm{met}}= & R_{1}^{0}+R_{2}^{0}+R_{7}^{0}+R_{11}^{0}+R_{12}^{0}+\frac{R_{13}}{4} \\
& +\frac{1}{1 / \sum_{k=3}^{6} R_{k}^{0}+1 / \sum_{j=8}^{10} R_{j}^{0}} .
\end{aligned}
$$

Since the relative permeability of the stator and rotor core of the AMB and the RMB unit is larger, their static magnetic 
reluctance can be ignored in the equivalent magnetic circuit of the bias flux path for calculating the dynamic displacement stiffness. The total static magnetic reluctance in (24) can be simplified as

$$
R_{\mathrm{met}}=R_{\mathrm{met}}^{0}+R_{\mathrm{met}}^{e} \approx R_{2}^{0}+\frac{R_{13}}{4}+\frac{1}{1 / R_{z 1}+1 / R_{z 2}}
$$

where,

$$
\begin{gathered}
R_{\mathrm{met}}^{0}=R_{2}^{0}+\frac{R_{13}}{4}+\frac{R_{z 1}^{0} R_{z 2}^{0}}{R_{z 1}^{0}+R_{z 2}^{0}}, \\
R_{\mathrm{met}}^{e}=\frac{\left(R_{z 2}^{0}-R_{z 1}^{0}\right) R_{z 1}^{d}-\left(R_{z 1}^{d}\right)^{2}}{R_{z 1}^{0}+R_{z 2}^{0}} .
\end{gathered}
$$

Since $\delta$ is smaller compared to $s_{0}$, then $R_{z i}^{d}(i=1,2)$ is smaller compared to $R_{z i}^{0}(i=1,2)$, and $R_{\text {met }}^{e}$ in (26) can be expanded into the power series and approximated by the first two terms as the higher order terms can be ignored. Consider the following:

$$
\begin{gathered}
R_{\mathrm{met}}^{0}=R_{2}^{0}+\frac{R_{13}}{4}+\frac{R_{z 1}^{0} R_{z 2}^{0}}{R_{z 1}^{0}+R_{z 2}^{0}}, \\
R_{\mathrm{met}}^{e} \approx \frac{\left(R_{z 2}^{0}-R_{z 1}^{0}\right) R_{z 1}^{d}}{R_{z 1}^{0}+R_{z 2}^{0}} .
\end{gathered}
$$

The flux in the air gap of AMB unit can be calculated as

$$
\begin{aligned}
& \phi_{z 1}=\frac{F_{m}}{R_{\mathrm{met}}^{0}+R_{\mathrm{met}}^{e}} \frac{1}{1 /\left(R_{z 1}^{0}+R_{z 1}^{d}\right)+1 /\left(R_{z 2}^{0}-R_{z 1}^{d}\right)} \frac{1}{R_{z 1}^{0}+R_{z 1}^{d}}, \\
& \phi_{z 2}=\frac{F_{m}}{R_{\mathrm{met}}^{0}+R_{\mathrm{met}}^{e}} \frac{1}{1 /\left(R_{z 1}^{0}+R_{z 1}^{d}\right)+1 /\left(R_{z 2}^{0}-R_{z 1}^{d}\right)} \frac{1}{R_{z 2}^{0}-R_{z 1}^{d}} .
\end{aligned}
$$

Substituting (27) for the right side of (28), since $R_{z i}^{d}$ is smaller compared to $R_{z i}^{0}$, (28) can be expanded into the power series and approximated by the first two terms as the higher order terms can be ignored. Consider the following:

$$
\begin{aligned}
& \phi_{z 1} \approx \frac{F_{m}}{R_{\mathrm{met}}^{0}} \frac{R_{z 1}^{0}}{R_{z 1}^{0}+R_{z 2}^{0}}\left[1-\frac{R_{z 1}^{d}}{R_{\mathrm{met}}^{0}}\left(\frac{R_{z 2}^{0}-R_{z 1}^{0}}{R_{z 1}^{0}+R_{z 2}^{0}}\right)-\frac{R_{z 1}^{d}}{R_{z 2}^{0}}\right], \\
& \phi_{z 2} \approx \frac{F_{m}}{R_{\mathrm{met}}^{0}} \frac{R_{z 2}^{0}}{R_{z 1}^{0}+R_{z 2}^{0}}\left[1-\frac{R_{z 1}^{d}}{R_{\mathrm{met}}^{0}}\left(\frac{R_{z 2}^{0}-R_{z 1}^{0}}{R_{z 1}^{0}+R_{z 2}^{0}}\right)+\frac{R_{z 1}^{d}}{R_{z 1}^{0}}\right] .
\end{aligned}
$$

The Equation (29) can be modified due to $R_{z 1}^{0}=R_{z 2}^{0}$.

$$
\begin{aligned}
& \phi_{z 1} \approx \frac{F_{m}}{2 R_{\mathrm{met}}^{0}}\left(1-\frac{A R_{z 1}^{d}}{R_{\mathrm{met}}^{0}}-\frac{R_{z 1}^{d}}{R_{z 2}^{0}}\right)=\phi_{z 0}\left(1-\frac{A R_{z 1}^{d}}{R_{\mathrm{met}}^{0}}-\frac{R_{z 1}^{d}}{R_{z 2}^{0}}\right), \\
& \phi_{z 2} \approx \frac{F_{m}}{2 R_{\mathrm{met}}^{0}}\left(1-\frac{A R_{z 1}^{d}}{R_{\mathrm{met}}^{0}}+\frac{R_{z 1}^{d}}{R_{z 1}^{0}}\right)=\phi_{z 0}\left(1-\frac{A R_{z 1}^{d}}{R_{\mathrm{met}}^{0}}+\frac{R_{z 1}^{d}}{R_{z 1}^{0}}\right),
\end{aligned}
$$

where $A=\left(R_{z 2}^{e t}-R_{z 1}^{e t}\right) /\left(R_{z 1}^{0}+R_{z 2}^{0}\right)$.
The AMB unit of the CRAMB will produce a net restoring force $f_{z i}$ on the thrust disk in $z$-axis direction, since the force is given by

$$
\begin{aligned}
f_{z s}= & \frac{\left(\phi_{z 1}\right)^{2}}{2 \mu_{0} A_{z}}-\frac{\left(\phi_{z 2}\right)^{2}}{2 \mu_{0} A_{z}} \\
= & \frac{\phi_{z 0}^{2}}{2 \mu_{0} A_{z}} \\
& \times\left[\left(1-\frac{A R_{z 1}^{d}}{R_{\mathrm{met}}^{0}}-\frac{R_{z 1}^{d}}{R_{z 2}^{0}}\right)^{2}-\left(1-\frac{A R_{z 1}^{d}}{R_{\mathrm{met}}^{0}}+\frac{R_{z 1}^{d}}{R_{z 1}^{0}}\right)^{2}\right],
\end{aligned}
$$

where $\phi_{z 0}=\phi_{z 1}^{0}=\phi_{z 2}^{0}=F_{m} / 2 R_{\text {met }}^{0}$ is the static bias flux in the air gap of the AMB unit.

Since $R_{z i}^{d}(i=1,2)$ is smaller compared to $R_{z i}^{0}(i=1,2)$, (31) can be expanded into the power series and approximated by the first two terms as the higher order terms can be ignored. Consider the following:

$$
f_{z s} \approx-\frac{2 \phi_{z 0}^{2}}{\left(\mu_{0} A_{z}\right)^{2}} \frac{\delta \sin (\omega t)}{R_{z 1}^{0}} .
$$

Static displacement stiffness of the AMB unit is given as

$$
\begin{aligned}
k_{z s}^{0} & =\frac{d f_{z s}}{d(\delta \sin (\omega t))}=-\frac{2 \phi_{z 0}^{2}}{\mu_{0} A_{z} s_{0}} \\
& =-\frac{1}{2 \mu_{0} A_{z} s_{0}}\left(\frac{F_{m}}{R_{2}^{0}+R_{13} / 4+R_{z 1}^{0} / 2}\right)^{2} .
\end{aligned}
$$

In the static analysis model mentioned above, the eddycurrent magnetic reluctance is not considered. However, the dynamic field should also cause eddy current, and the static model could be considered to include eddy-current magnetic reluctance as in the dynamic model. Then the dynamic flux including eddy-current effect is given as

$$
\begin{aligned}
& \phi_{z 1}^{d}=\phi_{z 1}^{0}\left(1-\frac{B R_{z 1}^{d}}{R_{\text {sum }}^{e t}}-\frac{R_{z 1}^{d}}{R_{z 2}^{e t}}\right), \\
& \phi_{z 2}^{d}=\phi_{z 2}^{0}\left(1-\frac{B R_{z 1}^{d}}{R_{\text {sum }}^{e t}}+\frac{R_{z 1}^{d}}{R_{z 1}^{e t}}\right),
\end{aligned}
$$


where,

$$
\begin{gathered}
R_{\mathrm{sum}}^{e t}=R_{\mathrm{sum}}^{0}+R_{\mathrm{sum}}^{\omega}, \\
R_{\mathrm{sum}}^{0}=R_{1}^{0}+R_{2}^{0}+R_{7}^{0}+R_{11}^{0}+R_{12}^{0}+\frac{R_{13}}{4}+\frac{R_{z 1}^{0}}{2}, \\
R_{\mathrm{sum}}^{\omega}=\sum_{m=1}^{2} R_{m}^{i}+R_{7}^{i}+\sum_{n=11}^{12} R_{n}^{i} \\
+\frac{1}{1 / \sum_{j=3}^{6} R_{j}+1 / \sum_{k=8}^{10} R_{k}}-\frac{R_{z 1}^{0}}{2}, \\
B=\frac{R_{z 2}^{e t}-R_{z 1}^{e t}}{R_{z 1}^{e t}+R_{z 2}^{e t}}, \\
R_{z 1}^{e t}=\sum_{j=3}^{6} R_{j}, \quad R_{z 2}^{e t}=\sum_{k=8}^{10} R_{k} .
\end{gathered}
$$

The permeability of the magnetic ring, stator core, rotor stator, and the thrust disk is compared to that of the air and the PMR, so (35) can be modified as

$$
\begin{gathered}
R_{\mathrm{sum}}^{0} \approx R_{2}^{0}+\frac{R_{13}}{4}+\frac{R_{z 1}^{0}}{2}, \\
R_{\mathrm{sum}}^{\omega} \approx \sum_{m=1}^{2} R_{m}^{i}+R_{7}^{i} \\
+\sum_{n=11}^{12} R_{n}^{i}+\frac{1}{1 / \sum_{j=3}^{6} R_{j}^{i}+1 / \sum_{k=8}^{10} R_{k}^{i}}-\frac{R_{z 1}^{0}}{2}, \\
R_{z 1}^{e t}=R_{3}^{i}+R_{4}^{i}+R_{5}^{i}+R_{6}^{0}, \\
R_{z 2}^{e t}=R_{8}^{0}+R_{9}^{i}+R_{10}^{i} .
\end{gathered}
$$

The net force of the AMB unit considering the eddycurrent magnetic reluctance is given by

$$
\begin{aligned}
f_{z s} & =\frac{\left(\phi_{z 1}^{d}\right)^{2}}{2 \mu_{0} A_{z}}-\frac{\left(\phi_{z 2}^{d}\right)^{2}}{2 \mu_{0} A_{z}} \\
& =\frac{\phi_{z 0}^{2}}{2 \mu_{0} A_{z}}\left[\left(1-\frac{B R_{z 1}^{d}}{R_{\text {sum }}^{e t}}-\frac{R_{z 1}^{d}}{R_{z 2}^{e t}}\right)^{2}-\left(1-\frac{B R_{z 1}^{d}}{R_{\text {sum }}^{e t}}+\frac{R_{z 1}^{d}}{R_{z 1}^{e t}}\right)^{2}\right] .
\end{aligned}
$$

Since $R_{z i}^{d}$ is smaller compared to $R_{z i}^{0}$, (37) can be expanded into the power series and approximated by the first two terms as the higher order terms can be ignored. Consider the following:

$$
f_{z s}^{d} \approx-\frac{2 \phi_{z 0}^{2}}{\left(\mu_{0} A_{z}\right)^{2}}\left(\frac{1}{2 R_{z 2}^{e t}}+\frac{1}{2 R_{z 1}^{e t}}\right) \delta \sin (\omega t) .
$$

The dynamic displacement stiffness considering the eddy-current magnetic reluctance is calculated as

$$
\begin{aligned}
k_{z s}^{d} & =\frac{d f_{z s}^{d}}{d(\delta \sin (\omega t))}=-\frac{2 \phi_{z 0}^{2}}{\mu_{0} A_{z} s_{0}}\left(\frac{R_{z 2}^{0}}{2 R_{z 2}^{e t}}+\frac{R_{z 1}^{0}}{2 R_{z 1}^{e t}}\right) \\
& =k_{z s}^{0}\left(\frac{R_{z 2}^{0}}{2 R_{z 2}^{e t}}+\frac{R_{z 1}^{0}}{2 R_{z 1}^{e t}}\right) .
\end{aligned}
$$

2.4. Dynamic Current Stiffness Model for the RMB Unit of $C R A M B$. The RMB unit controls the rotor movement along $x$-or (/and) $y$-axis orthogonal to the spin axis ( $z$-axis). When the rotor deviates radially from its "suspended" position at $x$ axis (the magnetomotive force at $y$-axis, $N_{r} i_{y}=0$ ), the net restoring force of the RMB unit at $x$-axis, $f_{x i}$, can be given as

$$
f_{x i}=\frac{\phi_{x 1}^{2}}{2 \mu_{0} A_{r}}-\frac{\phi_{x 2}^{2}}{2 \mu_{0} A_{r}},
$$

where,

$$
\begin{gathered}
\phi_{x 1}=\phi_{r m}+\phi_{x 1}^{i}, \\
\phi_{x 2}=\phi_{r m}-\phi_{x 2}^{i}, \quad \phi_{r m}=\frac{\phi_{m 0}}{4} .
\end{gathered}
$$

The flux in the air gap of the RMB unit produced by the $x$-axis coil current, $i_{x}$, is calculated as

$$
\begin{aligned}
\phi_{x 1}^{i}= & \frac{N_{r} i_{x}}{R_{x 1}+1 /\left(1 / R_{x 2}+1 / R_{y 1}+1 / R_{y 2}\right)} \\
& +\frac{N_{r} i_{x}}{R_{x 2}+1 /\left(1 / R_{x 1}+1 / R_{y 1}+1 / R_{y 2}\right)} \\
& \times \frac{1}{1 / R_{x 1}+1 / R_{y 1}+1 / R_{y 2}} \frac{1}{R_{x 1}}, \\
\phi_{x 2}^{i}= & \frac{N_{r} i_{x}}{R_{x 2}+1 /\left(1 / R_{x 1}+1 / R_{y 1}+1 / R_{y 2}\right)} \\
& +\frac{N_{r} i_{x}}{R_{x 1}+1 /\left(1 / R_{x 2}+1 / R_{y 1}+1 / R_{y 2}\right)} \\
& \times \frac{1}{1 / R_{x 2}+1 / R_{y 1}+1 / R_{y 2}} \frac{1}{R_{x 2}} .
\end{aligned}
$$

The nominal magnetic reluctances of the air gap in RMB unit are equal to each other when the rotor locates its center position, $R_{x}=R_{x 1}=R_{x 2}=R_{y}=R_{y 1}=R_{y 2}$. Then (42) can be modified as

$$
\phi_{x}^{i}=\phi_{x 2}^{i}=\phi_{x 2}^{i}=\frac{N_{r} i_{x}}{R_{x}} .
$$

Substituting (43) for the right side of (40), (40) can be modified as

$$
f_{x i}=\frac{2 \phi_{r m}}{\mu_{0} A_{r}} \frac{N_{r} i_{x}}{R_{x}} .
$$


The eddy-current reluctance can be ignored due to laminated rotor and stator core, and the controls current do not pass through the other nonlaminated materials. So the dynamic current stiffness of the RMB unit will be equal to its static stiffness. Consider the following:

$$
k_{r i}^{i}=k_{r i}^{0}=\frac{d f_{x i}}{d i_{x}}=\frac{2 \phi_{r m} N_{r}}{\mu_{0} A_{r} R_{x}}=\frac{N_{r}}{2 \mu_{0} A_{r} R_{x}} \frac{F_{m}}{R_{2}^{0}+R_{13} / 4+R_{z 1}^{0} / 2} .
$$

\subsection{Dynamic Displacement Stiffness Model for the RMB Unit} of CRAMB. When the coil currents in the RMB and the AMB unit are zero, the air gap in the AMB unit remains stationary, but the air gap in the RMB unit varies sinusoidally about the nominal value $s_{0}$ in $x$-axis; that is, $x_{1}=s_{0}+\delta \sin (\omega t)$ in upper air gap; and $x_{2}=s_{0}-\delta \sin (\omega t)$ in lower air gap, then the magnetic reluctance of the air gap will also vary sinusoidally about the nominal value. Thus, the reluctance of the two air gaps in the RMB unit includes two parts, one is the static reluctance, $R_{x}^{0}$, and the other one is the dynamic reluctance, $R_{x}^{d}$. Consider the following:

$$
\begin{aligned}
& R_{x 1}=R_{x}^{0}+R_{x}^{d}=\frac{s_{0}}{\mu_{0} A_{r}}+\frac{\delta \sin (\omega t)}{\mu_{0} A_{r}}, \\
& R_{x 2}=R_{x}^{0}-R_{x}^{d}=\frac{s_{0}}{\mu_{0} A_{r}}-\frac{\delta \sin (\omega t)}{\mu_{0} A_{r}},
\end{aligned}
$$

where

$$
R_{x}^{0}=\frac{s_{0}}{\mu_{0} A_{r}}, \quad R_{x}^{d}=\frac{\delta \sin (\omega t)}{\mu_{0} A_{r}} .
$$

If all the leakage reluctances and eddy-current reluctance are ignored, the total reluctance $R_{\text {met }}$ in the bias magnetic circuit is

$$
\begin{aligned}
R_{\mathrm{met}}= & \sum_{j=1}^{2} R_{j}^{0}+R_{7}^{0}+\sum_{k=11}^{12} R_{k}^{0} \\
& +\frac{1}{2 / R_{y}+1 / R_{x 1}+1 / R_{x 2}}+\frac{1}{1 / \sum_{k=3}^{6} R_{k}^{0}+1 / \sum_{j=8}^{10} R_{j}^{0}} .
\end{aligned}
$$

The relative permeability of the stator and rotor core is lager compared to the air gap, then their static reluctance can be ignored in the equivalent magnetic circuit of the bias flux path for calculated the dynamic displacement stiffness. The total reluctance in (48) can be simplified as

$$
R_{\mathrm{met}}=R_{\mathrm{met}}^{0}+R_{\mathrm{met}}^{e} \approx R_{2}^{0}+\frac{1}{2 / R_{y}+1 / R_{x 1}+1 / R_{x 2}}+\frac{R_{z 1}^{0}}{2},
$$

where,

$$
\begin{gathered}
R_{\mathrm{met}}^{0}=R_{2}^{0}+\frac{R_{x}^{0}}{4}+\frac{R_{z 1}^{0}}{2}, \\
R_{\mathrm{met}}^{e}=\frac{1}{2 / R_{x}^{0}+1 / R_{x 1}+1 / R_{x 2}}-\frac{R_{x}^{0}}{4} .
\end{gathered}
$$

Since dynamic magnetic reluctance is smaller compared to static magnetic reluctance of the air gap, $R_{\text {met }}^{e}$ can be expanded into the power series and approximated by the first two terms as the higher order terms can be ignored, and the $R_{\text {met }}^{e}$ will approximately equal to zero, $R_{\text {met }}^{e} \approx 0$.

The flux in the upper and lower air gap of RMB in $x$-axis is calculated, respectively. Consider the following:

$$
\begin{aligned}
& \phi_{x 1}=\frac{F_{m}}{R_{\text {met }}} \frac{1}{2 / R_{x}^{0}+1 / R_{x 1}+1 / R_{x 2}} \frac{1}{R_{x 1}}, \\
& \phi_{x 2}=\frac{F_{m}}{R_{\text {met }}} \frac{1}{2 / R_{x}^{0}+1 / R_{x 1}+1 / R_{x 2}} \frac{1}{R_{x 2}} .
\end{aligned}
$$

Substituting (46) for the right side of (51), since $R_{x}^{d}$ is smaller compared to $R_{x}^{0}$, (51) can be expanded into the power series and approximated by the first two terms as the higher order terms can be ignored. Consider the following:

$$
\begin{aligned}
& \phi_{x 1}=\frac{F_{m}}{4 R_{\mathrm{met}}}\left(1-\frac{R_{x}^{d}}{R_{x}^{0}}\right)=\phi_{x 0}\left(1-\frac{R_{x}^{d}}{R_{x}^{0}}\right) \\
& \phi_{x 2}=\frac{F_{m}}{4 R_{\mathrm{met}}}\left(1+\frac{R_{x}^{d}}{R_{x}^{0}}\right)=\phi_{x 0}\left(1+\frac{R_{x}^{d}}{R_{x}^{0}}\right),
\end{aligned}
$$

where $\phi_{x 0}=F_{m} / 4 R_{\text {met }}$.

The net force produced by RMB unit in $x$-axis is given by

$$
\begin{aligned}
f_{x s} & =\frac{\left(\phi_{x 1}\right)^{2}}{2 \mu_{0} A_{r}}-\frac{\left(\phi_{x 2}\right)^{2}}{2 \mu_{0} A_{r}} \\
& =\frac{\phi_{x 0}^{2}}{2 \mu_{0} A_{r}}\left[\left(1-\frac{R_{x}^{d}}{R_{x}^{0}}\right)^{2}-\left(1+\frac{R_{x}^{d}}{R_{x}^{0}}\right)^{2}\right] \\
& =-\frac{2 \phi_{x 0}^{2}}{\left(\mu_{0} A_{r}\right)^{2}} \frac{\delta \sin (\omega t)}{R_{x}^{0}} .
\end{aligned}
$$

The static displacement stiffness is calculated by

$$
k_{r s}^{0}=\frac{d f_{x s}}{d(\delta \sin (\omega t))}=-\frac{2 \phi_{x 0}^{2}}{\mu_{0} A_{r} s_{0}} .
$$

In the static analysis model mentioned above, the eddycurrent magnetic reluctance is not considered. However, the dynamic field should also cause eddy current, and the static model could be considered to include eddy-current magnetic reluctance as in the dynamic model. Then the dynamic flux in air gap of RMB unit in $x$-axis including eddy-current effect is given as

$$
\begin{aligned}
& \phi_{x 1}=\frac{F_{m}}{R_{\text {sum }}^{\text {et }}} \frac{1}{2 / R_{x}^{0}+1 / R_{x 1}+1 / R_{x 2}} \frac{1}{R_{x 1}}, \\
& \phi_{x 2}=\frac{F_{m}}{R_{\text {sum }}^{\text {et }}} \frac{1}{2 / R_{x}^{0}+1 / R_{x 1}+1 / R_{x 2}} \frac{1}{R_{x 2}},
\end{aligned}
$$


where $R_{\text {sum }}^{e t}=R_{\text {sum }}^{0}+R_{\text {sum }}^{\omega}, R_{\text {sum }}^{0}$, and $R_{\text {sum }}^{\omega}$ are given as

$$
\begin{aligned}
R_{\mathrm{sum}}^{0}= & \sum_{m=1}^{2} R_{m}^{0}+R_{7}^{0} \\
& +\sum_{n=11}^{12} R_{n}^{0}+\frac{1}{2 / R_{x}^{0}+1 / R_{x 1}+1 / R_{x 2}}+\frac{R_{z 1}^{0}}{2}, \\
R_{\mathrm{sum}}^{\omega}= & \sum_{m=1}^{2} R_{m}^{i}+R_{7}^{i} \\
& +\sum_{n=11}^{12} R_{n}^{i}+\frac{1}{1 / \sum_{j=3}^{6} R_{j}+1 / \sum_{k=8}^{10} R_{k}}-\frac{R_{z 1}^{0}}{2} .
\end{aligned}
$$

The permeability of the magnetic ring, stator core, rotor stator, and the thrust disk is compared to that of the air and the PMB, so (56) can be modified as

$$
\begin{aligned}
R_{\mathrm{sum}}^{0}= & R_{2}^{0}+\frac{1}{2 / R_{x}^{0}+1 / R_{x 1}+1 / R_{x 2}}+\frac{R_{z 1}^{0}}{2}, \\
R_{\mathrm{sum}}^{\omega}= & \sum_{m=1}^{2} R_{m}^{i}+R_{7}^{i}+\sum_{n=11}^{12} R_{n}^{i} \\
& +\frac{1}{1 / \sum_{j=3}^{6} R_{j}+1 / \sum_{k=8}^{10} R_{k}}-\frac{R_{z 1}^{0}}{2} .
\end{aligned}
$$

And (55) can be expanded into the power series and approximated by the first two terms as the higher order terms can be ignored.

$$
\begin{aligned}
& \phi_{x 1}=\frac{F_{m}}{R_{\text {sum }}^{\text {et }}}\left(1-\frac{R_{x}^{d}}{R_{x}^{0}}\right)=\phi_{x}^{0} \frac{R_{\mathrm{met}}}{R_{\mathrm{sum}}^{\text {et }}}\left(1-\frac{R_{x}^{d}}{R_{x}^{0}}\right), \\
& \phi_{x 2}=\frac{F_{m}}{R_{\text {sum }}^{\text {et }}}\left(1+\frac{R_{x}^{d}}{R_{x}^{0}}\right)=\phi_{x}^{0} \frac{R_{\mathrm{met}}}{R_{\mathrm{sum}}^{e t}}\left(1+\frac{R_{x}^{d}}{R_{x}^{0}}\right) .
\end{aligned}
$$

The net force produced by the RMB unit considering the eddy-current magnetic reluctance is modified by

$$
f_{x s}^{d}=\frac{\left(\phi_{x 1}\right)^{2}}{2 \mu_{0} A_{r}}-\frac{\left(\phi_{x 2}\right)^{2}}{2 \mu_{0} A_{r}} .
$$

Substituting (58) for the right side of (59), (59) is modified as

$$
f_{x s}^{d}=\frac{\left(\phi_{x 1}\right)^{2}}{2 \mu_{0} A_{r}}-\frac{\left(\phi_{x 2}\right)^{2}}{2 \mu_{0} A_{r}}=-\frac{2 \phi_{x 0}^{2}}{\left(\mu_{0} A_{r}\right)^{2}}\left(\frac{R_{\mathrm{met}}}{R_{\mathrm{sum}}^{e t}}\right)^{2} \frac{\delta \sin (\omega t)}{R_{x}^{0}} .
$$

The dynamic displacement stiffness of RMB unit considering the eddy-current effect is given by

$$
k_{r s}^{d}=\frac{d f_{x s}}{d(\delta \sin (\omega t))}=-\frac{2 \phi_{x 0}^{2}}{\mu_{0} A_{z} s_{0}}\left(\frac{R_{\mathrm{met}}}{R_{\mathrm{sum}}^{\text {et }}}\right)^{2}=k_{r s}^{0}\left(\frac{R_{\mathrm{met}}}{R_{\mathrm{sum}}^{e t}}\right)^{2} .
$$

\section{Coupling Performance Analysis of the Dynamic Stiffness Models of CRAMB}

Since the equivalent magnetic circuits of control flux path of the $\mathrm{AMB}$ and $\mathrm{RMB}$ unit do not influence each other, the current stiffness of AMB (or RMB) unit will not be affected by the control current of the RMB (or AMB) unit. But the equivalent bias circuits of the $A M B$ and the $R M B$ pass through the $\mathrm{PMB}$, and the dynamic models of the $\mathrm{AMB}$ and the RMB unit may influence each other due the air gap varying of the $\mathrm{AMB}$ or $\mathrm{RMB}$ unit.

3.1. The Dynamic Current Stiffness of the AMB Unit Affected by the Rotor Position of RMB Unit in $x$-Axis. Based on the small variation of the rotor position of the RMB unit in $x$ axis, $x_{1}=s_{0}+x, x_{2}=s_{0}-x$, and the remains stationary in $y$-axis $(y 1=y 2=s 0)$.

The static bias flux in the air gap of the AMB unit is modified as

$$
\begin{aligned}
\phi_{z m 0}^{r} & =\phi_{z 1}^{r 0}=\phi_{z 2}^{r 0}=\frac{\phi_{m 0}^{r}}{2} \\
& =\frac{F_{m}}{R_{2}^{0}+1 /\left(2 / R_{x}^{0}+1 / R_{x 1}+1 / R_{x 2}\right)+R_{z 1}^{0} / 2} \\
& =\frac{F_{m}}{R_{2}^{0}+1 /\left(2 \mu_{0} A_{r} / s_{0}+2 \mu_{0} A_{r} s_{0} /\left(s_{0}^{2}-x^{2}\right)\right)+R_{z 1}^{0} / 2} .
\end{aligned}
$$

And the dynamic current stiffness of the AMB unit is modified due to rotor position varying in $x$-axis. Consider the following:

$$
\begin{aligned}
k_{z i}^{r i}= & \frac{2 N_{z}}{\mu_{0} A_{z} R_{z i}^{0}(1+\lambda)} \\
& \times \frac{F_{m}}{R_{2}^{0}+1 /\left(2 \mu_{0} A_{r} / s_{0}+2 \mu_{0} A_{r} s_{0} /\left(s_{0}^{2}-x^{2}\right)\right)+R_{z 1}^{0} / 2} \\
= & k_{z i}^{i} \frac{R_{2}^{0}+R_{13} / 4+R_{z 1}^{0} / 2}{R_{2}^{0}+1 /\left(2 \mu_{0} A_{r} / s_{0}+2 \mu_{0} A_{r} s_{0} /\left(s_{0}^{2}-x^{2}\right)\right)+R_{z 1}^{0} / 2} \\
= & k_{z i}^{i} \lambda_{r z},
\end{aligned}
$$

where $\lambda_{r z}=\left(R_{2}^{0}+R_{13} / 4+R_{z 1}^{0} / 2\right) /\left(R_{2}^{0}+1 /\left(2 \mu_{0} A_{r} / s_{0}+\right.\right.$ $\left.\left.2 \mu_{0} A_{r} s_{0} /\left(s_{0}^{2}-x^{2}\right)\right)+R_{z 1}^{0} / 2\right)$ is the coefficient which reflects the dynamic current stiffness dependence of the AMB unit on the rotor position in $x$-axis (or $y$-axis). In other words, the coefficient, $\lambda_{r z}$, reflects the coupling extent of the dynamic current stiffness of the AMB unit affected by the rotor position in $x$-axis or $y$-axis.

From (63), the $x$ term is included in the dynamic current stiffness model which will be affected by the rotor position of the RMB unit in $x$-axis or $y$-axis.

3.2. The Dynamic Displacement Stiffness of the AMB Unit Affected by the Rotor Position of RMB Unit in $x$-Axis. The 
$R_{\text {sum }}^{0}$ in (36) will be modified when considering the small variation of the rotor position of the RMB unit in $x$-axis. Consider the following:

$$
R_{\text {sum }}^{0}=R_{2}^{0}+\frac{1}{2 \mu_{0} A_{r} / s_{0}+2 \mu_{0} A_{r} s_{0} /\left(s_{0}^{2}-x^{2}\right)}+\frac{R_{z 1}^{0} R_{z 2}^{0}}{R_{z 1}^{0}+R_{z 2}^{0}} .
$$

And the dynamic displacement stiffness is modified due to rotor position varying in $x$-axis. Consider the following:

$$
\begin{aligned}
k_{z s}^{r d} & \\
= & -\frac{1}{2 \mu_{0} A_{z} s_{0}} \\
& \times\left(\frac{F_{m}}{R_{2}^{0}+1 /\left(2 \mu_{0} A_{r} / s_{0}+2 \mu_{0} A_{r} s_{0} /\left(s_{0}^{2}-x^{2}\right)\right)+R_{z 1}^{0} / 2}\right)^{2} \\
& \times\left(\frac{R_{z 1}^{0}}{2 R_{z 2}^{e t}}+\frac{R_{z 2}^{0}}{2 R_{z 1}^{e t}}\right) \\
= & k_{z s}^{d} \frac{\left(R_{2}^{0}+R_{13} / 4+R_{z 1}^{0} / 2\right)^{2}}{\left(R_{2}^{0}+1 /\left(2 \mu_{0} A_{r} / s_{0}+2 \mu_{0} A_{r} s_{0} /\left(s_{0}^{2}-x^{2}\right)\right)+R_{z 1}^{0} / 2\right)^{2}} \\
= & k_{z s}^{d} \lambda_{r z}^{2}
\end{aligned}
$$

From (65), the $x$ term is included in the dynamic displacement stiffness model which will be affected by the rotor position of the RMB unit in $x$-axis or $y$-axis. And $\lambda_{r z}^{2}$ is the coefficient which reflects the dynamic displacement stiffness of the AMB unit dependence on the rotor position in $x$-axis (or $y$-axis). In other words, the coefficient, $\lambda_{r z}^{2}$, reflects the coupling extent of the dynamic displacement stiffness of the AMB unit affected by the rotor position in $x$-axis or $y$ axis.

3.3. The Dynamic Current Stiffness of the RMB Unit Affected by the Rotor Position of $A M B$ Unit in $z$-Axis. Based on the small variation of the rotor position of the AMB unit in $z$ axis, $z_{1}=s_{0}+z, z_{2}=s_{0}-z$, and the remains stationary in $y$-axis $\left(R_{y 1}=R_{y 2} \approx R_{x}^{0}\right)$. The magnetic reluctance of the air gap for the AMB unit can be modified as

$$
R_{z 1}=\frac{s_{0}+z}{\mu_{0} A_{z}}, \quad R_{z 2}=\frac{s_{0}-z}{\mu_{0} A_{z}} .
$$

The static bias flux in the air gap of the RMB unit affected by the rotor position in $z$-axis varying is modified as

$$
\begin{aligned}
\phi_{r m} & =\frac{\phi_{m 0}}{4}=\frac{F_{m} / 4}{R_{2}^{0}+R_{13} / 4+1 /\left(1 / R_{z 1}+1 / R_{z 2}\right)} \\
& =\frac{F_{m} / 4}{R_{2}^{0}+R_{13} / 4+\left(s_{0}^{2}-z^{2}\right) / 2 \mu_{0} A_{z} s_{0}} .
\end{aligned}
$$

And the dynamic current stiffness of the RMB unit affected by the rotor position varying in $z$-axis is modified as

$$
\begin{aligned}
k_{r i}^{z i} & =\frac{d f_{x i}}{d i_{x}}=\frac{2 \phi_{r m} N_{r}}{\mu_{0} A_{r} R_{x}} \\
& =\frac{N_{r}}{2 \mu_{0} A_{r} R_{x}} \frac{F_{m}}{R_{2}^{0}+R_{x} / 4+\left(s_{0}^{2}-z^{2}\right) / 2 \mu_{0} A_{z} s_{0}} \\
& =k_{r i}^{i} \frac{R_{2}^{0}+R_{x} / 4+R_{z 1}^{0} / 2}{R_{2}^{0}+R_{x} / 4+\left(s_{0}^{2}-z^{2}\right) / 2 \mu_{0} A_{z} s_{0}}=k_{r i}^{i} \lambda_{z r},
\end{aligned}
$$

where $\lambda_{z r}=\left(R_{2}^{0}+R_{x} / 4+R_{z 1}^{0} / 2\right) /\left(R_{2}^{0}+R_{x} / 4+\left(s_{0}^{2}-\right.\right.$ $\left.\left.z^{2}\right) / 2 \mu_{0} A_{z} s_{0}\right)$.

Base on (65), the $z$ term is included in the dynamic current stiffness model which will be affected by the rotor position varying in $z$-axis.

3.4. The Dynamic Displacement Stiffness of the RMB Unit Affected by the Rotor Position of $A M B$ Unit in $z$-Axis. The total static magnetic reluctance will be modified when considering the small variation of the rotor position of the $\mathrm{AMB}$ unit in $z$-axis. Consider the following:

$$
R_{\mathrm{met}}=R_{2}^{0}+\frac{R_{x}^{0}}{4}+\frac{1}{1 / R_{z 1}^{0}+1 / R_{z 2}^{0}}=R_{2}^{0}+\frac{R_{x}^{0}}{4}+\frac{s_{0}^{2}-z^{2}}{2 \mu_{0} A_{z} s_{0}} .
$$

The static bias flux in the air gap of the RMB unit is modified when considering the rotor position varying of the $\mathrm{AMB}$ unit in $z$-axis. Consider the following:

$$
\phi_{x}^{0}=\frac{F_{m}}{4 R_{\text {met }}}=\frac{F_{m}}{4\left(R_{2}^{0}+R_{x}^{0} / 4+\left(s_{0}^{2}-z^{2}\right) / 2 \mu_{0} A_{z} s_{0}\right)} .
$$

The total dynamic magnetic reluctance affected by the eddy-current effect is modified as

$$
\begin{aligned}
R_{\text {sum }}^{e t}= & \sum_{m=1}^{2} R_{m}+R_{7}+\sum_{n=11}^{12} R_{n}+\frac{1}{2 / R_{x}^{0}+1 / R_{x 1}+1 / R_{x 2}} \\
& +\frac{1}{1 / \sum_{j=3}^{6} R_{j}+1 / \sum_{k=8}^{10} R_{k}}+\frac{s_{0}^{2}-z^{2}}{2 \mu_{0} A_{z} s_{0}} .
\end{aligned}
$$

The relative permeability of the stator and rotor core is larger compared to that of the air gap and the permanent magnet. Then (71) can be simplified.

Due to rotor position varying in $z$-axis, the dynamic displacement stiffness of the RMB unit is modified as

$$
\begin{aligned}
k_{r s}^{z d} & =\frac{d f_{x s}}{d(\delta \sin (\omega t))} \\
& =-\frac{F_{m}^{2} /\left(R_{2}^{0}+R_{x}^{0} / 4+\left(s_{0}^{2}-z^{2}\right) / 2 \mu_{0} A_{z} s_{0}\right)^{2}}{8 \mu_{0} A_{z} s_{0}}\left(\frac{R_{\text {met }}}{R_{\text {sum }}^{\text {et }}}\right)^{2} \\
& =k_{r s}^{d} \lambda_{z r}^{2} .
\end{aligned}
$$




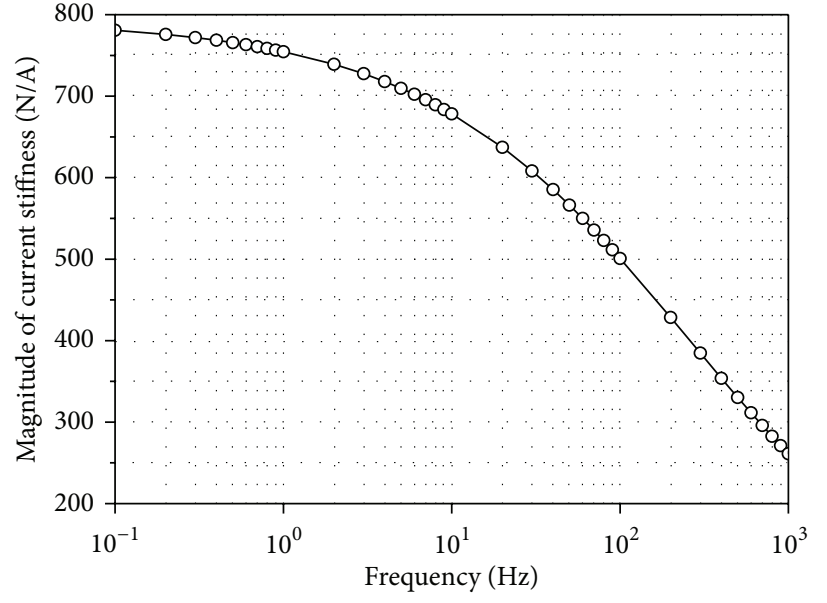

(a)

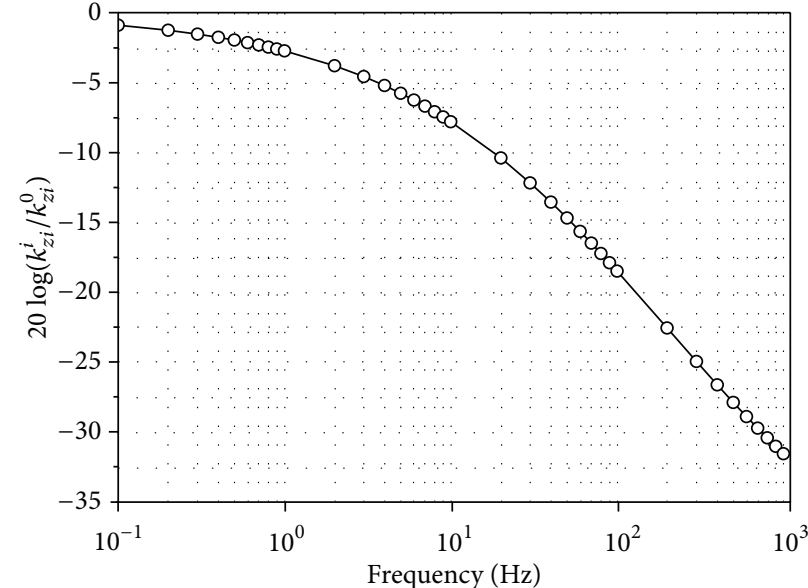

(b)

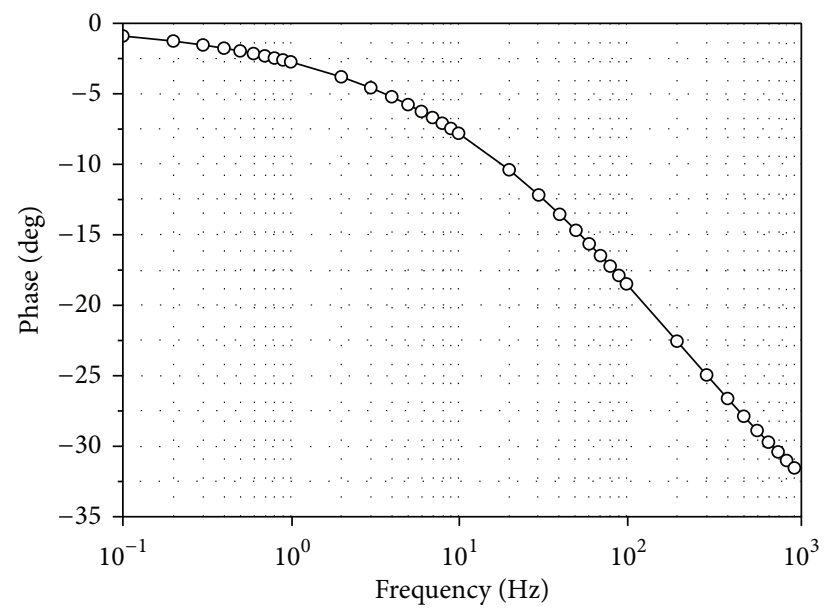

(c)

FIGURE 6: Frequency response of the dynamic current stiffness of AMB unit. (a) The magnitude of the dynamic current stiffness of AMB unit. (b) The magnitude of the ratio of the dynamic current stiffness to the static current stiffness of the AMB unit. (c) The phase of the ratio, $k_{z i}^{i} / k_{z i}^{0}$, of the dynamic current stiffness to the static current stiffness of the AMB unit.

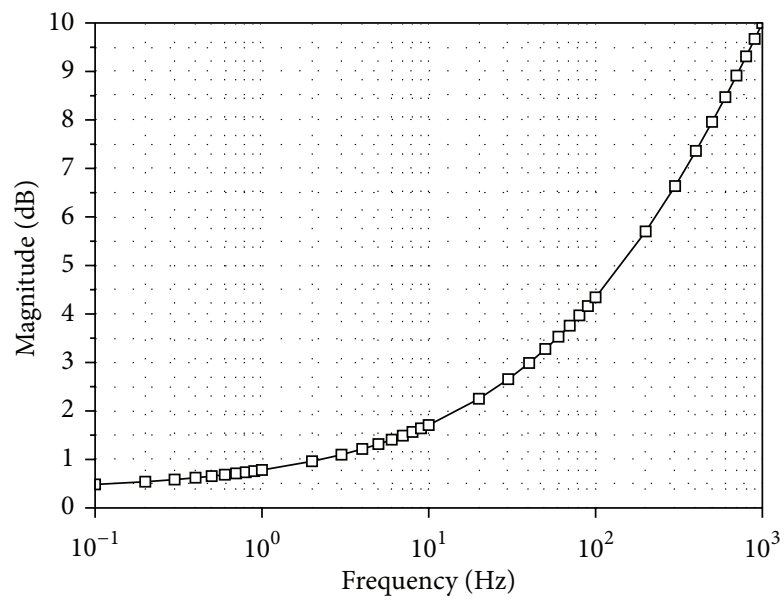

FIgURE 7: The magnitude of the ratio of the total dynamic reluctance to the total static reluctance in equivalent control flux path of the AMB unit, $20 \log _{10}\left(R_{e}(\omega) / R_{z i}^{0}\right)$. 


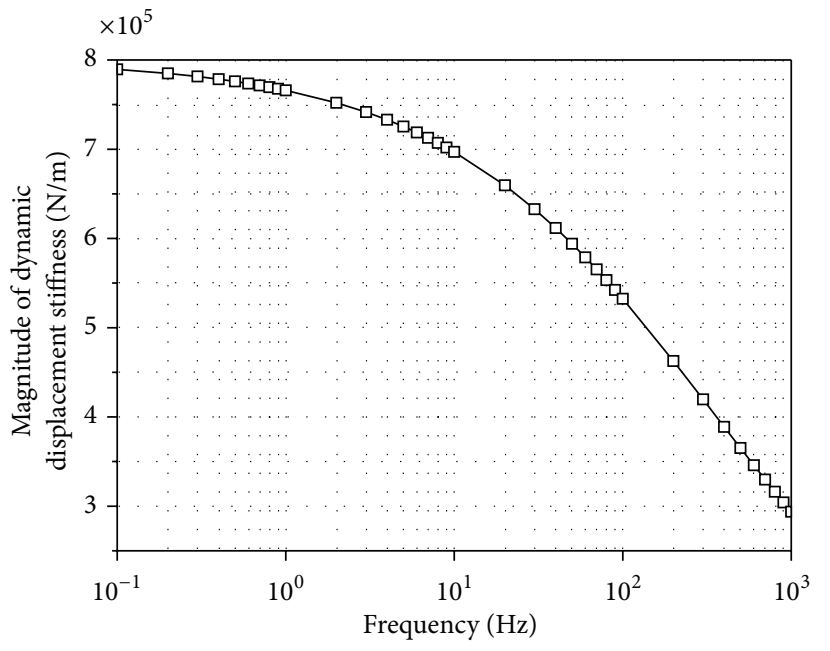

(a)

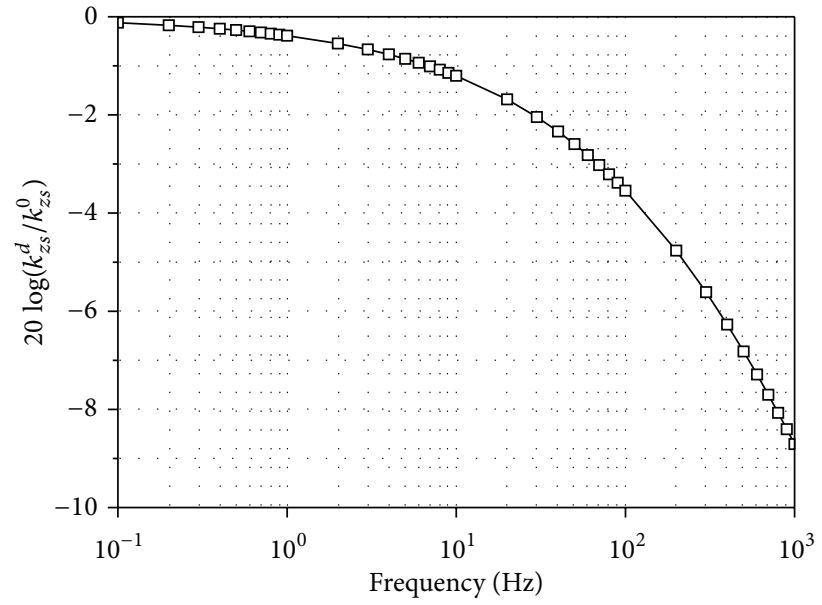

(b)

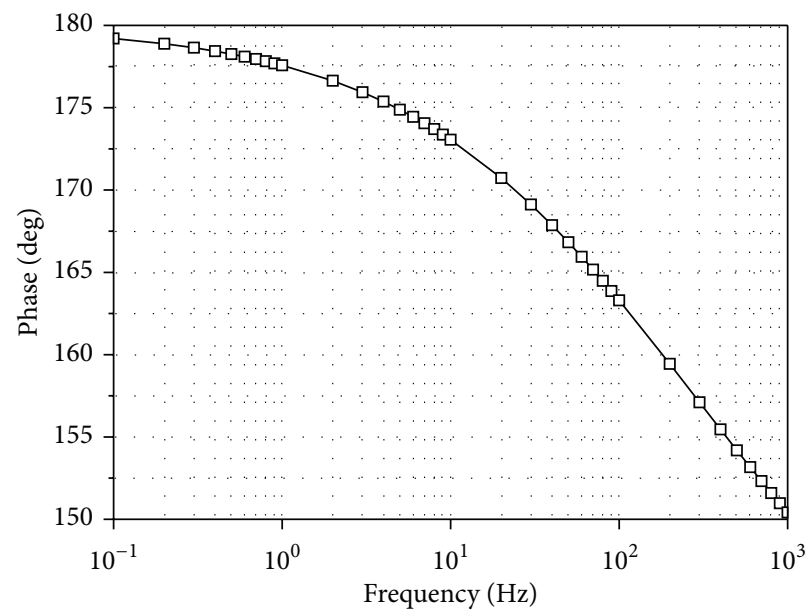

(c)

FIGURE 8: Frequency response of the dynamic displacement stiffness of the AMB unit. (a) The magnitude of the dynamic displacement stiffness of the AMB unit. (b) The magnitude of the ratio of the dynamic displacement stiffness to the static displacement stiffness of the AMB unit. (c) The phase of the ratio, $k_{z s}^{d} / k_{z s}^{0}$, of the dynamic displacement stiffness to the static displacement stiffness of the AMB unit.

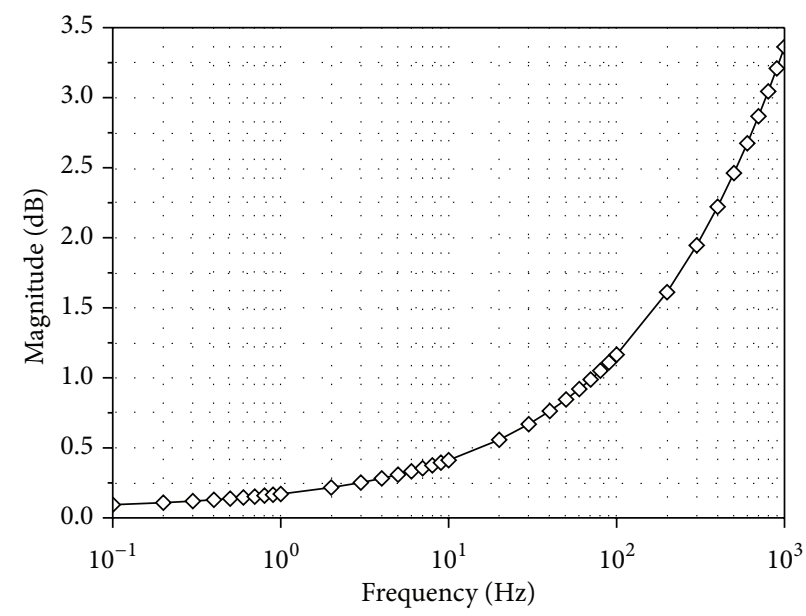

FIGURE 9: The magnitude of the ratio of the total dynamic reluctance to the total static reluctance in equivalent bias flux path of the CRAMB, $20 \log _{10}\left(R_{\text {sum }}^{e t} / R_{\text {sum }}^{0}\right)$. 


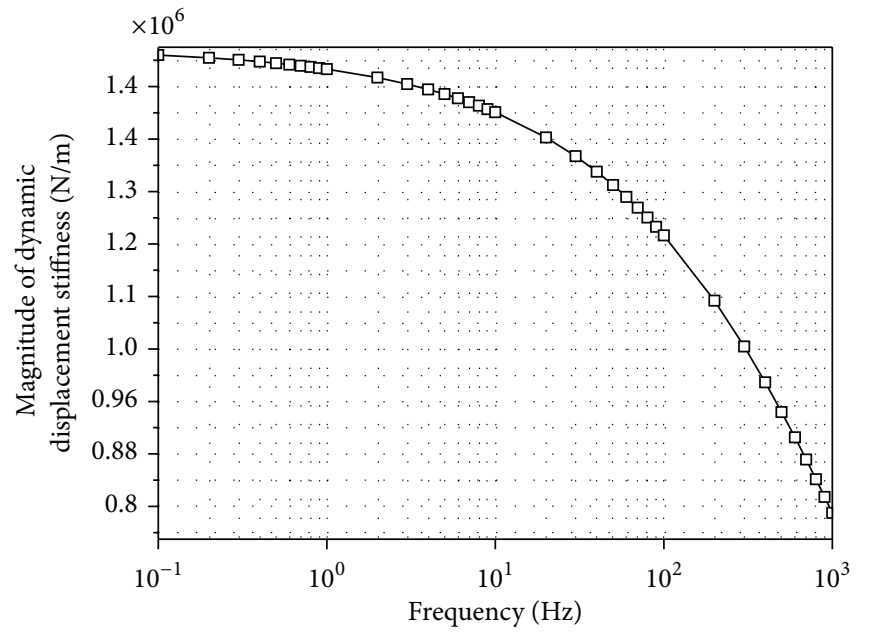

(a)

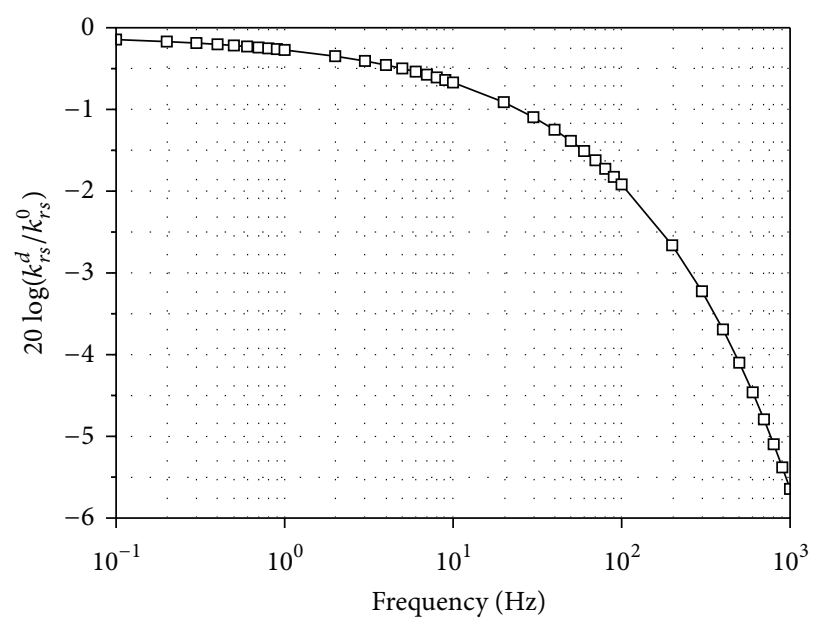

(b)

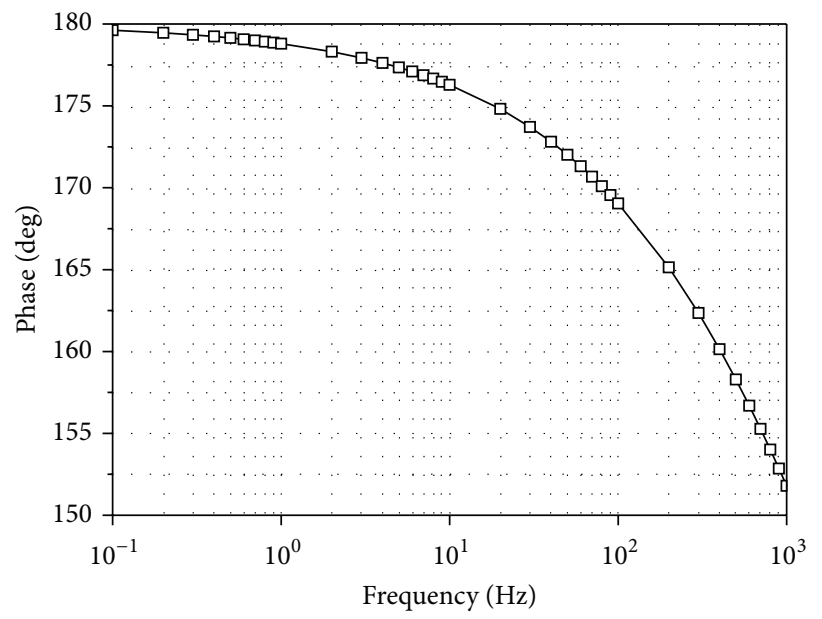

(c)

Figure 10: Frequency response of the dynamic displacement stiffness of the RMB unit. (a) The dynamic displacement stiffness of the RMB unit. (b) The ratio of the dynamic displacement stiffness to the static displacement stiffness of the RMB unit (c) Phase of $k_{r s}^{d} / k_{r s}^{0}$.

Based on (72), the $z$ term is included in the dynamic displacement stiffness model which will be affected by the rotor position varying in $z$-axis.

\section{Example and Results}

Based on the methods mentioned above, the CRAMB with permanent magnet is designed. The configuration of the CRAMB studied is shown in Figure 1. The related parameters are shown in Table 1.

The static current stiffness and displacement stiffness of the CRAMB could be calculated by linearized model with a small perturbation of the current or air gap. The static current stiffness, $k_{z i}^{0}$, and displacement stiffness, $k_{z s}^{0}$, of the AMB unit are $825.6 \mathrm{~N} / \mathrm{A}$ and $-8.0067 \times 10^{5} \mathrm{~N} / \mathrm{m}$, respectively. The static current stiffness, $k_{r i}^{0}$, and displacement stiffness, $k_{r s}^{0}$, of the $\mathrm{RMB}$ unit are $756.8 \mathrm{~N} / \mathrm{A}$ and $-1.5131 \times 10^{6} \mathrm{~N} / \mathrm{m}$, respectively.
The magnitude and phase plots of the dynamic current stiffness of the AMB unit are shown in Figure 6. It is obvious that the dynamic current stiffness is affected by the varying frequency of the control current of the AMB unit. And this can be shown in Figure 7. Figure 7 gives the magnitude of the ratio of the total dynamic reluctance to the total static reluctance in equivalent control flux path of the AMB unit, $20 \log _{10}\left(R_{e}(\omega) / R_{z i}^{0}\right)$. The dynamic reluctance of the control flux path of the AMB unit will increase with the varying frequency of the control current in the AMB coil current.

The magnitude and phase plots of the dynamic displacement stiffness of the AMB unit are shown in Figure 8. It is obvious that the dynamic displacement stiffness is also affected by the varying frequency of the rotor position of the AMB unit in $z$-axis. From Figures 6 and 8 , we can see that the response bandwidth of the dynamic displacement is higher compared to that of the dynamic current stiffness. And this can be explained by Figure 9, which shows the magnitude of the ratio of the total dynamic reluctance to 


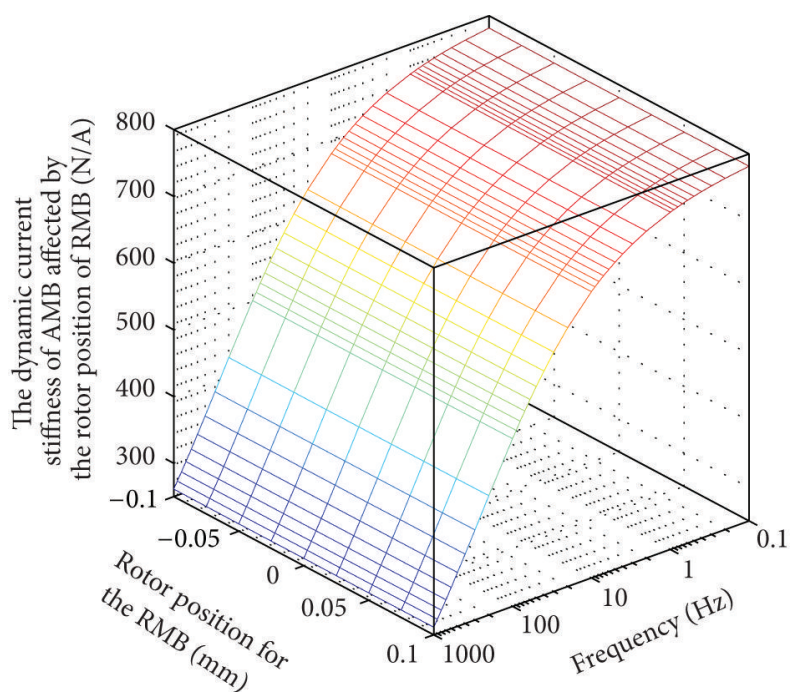

FIGURE 11: The magnitude of the dynamic current stiffness versus varying frequency of the control current in $\mathrm{AMB}$ unit and the rotor position of RMB unit in $x$-axis.

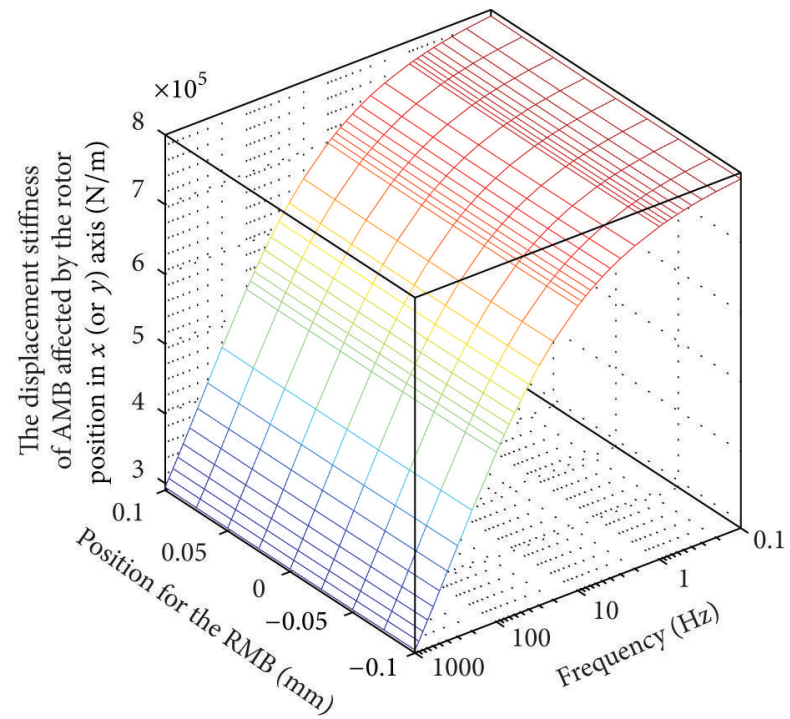

Figure 12: The magnitude of the dynamic displacement stiffness versus varying frequency of the rotor position of the AMB unit in $z$-axis and the rotor position of RMB unit in $x$-axis.

the total static reluctance in equivalent bias flux path of the CRAMB, $20 \log _{10}\left(R_{\text {sum }}^{e t} / R_{\text {sum }}^{0}\right)$. The dynamic reluctance of the bias flux path will increase with the varying frequency.

The magnitude and phase plots of the dynamic displacement stiffness of the RMB unit are shown in Figure 10. It is obvious that the dynamic displacement stiffness is also affected by the varying frequency of the rotor position of the RMB unit in $x$-axis. From Figures 8 and 10, we can see that the response bandwidth of the dynamic displacement of the AMB unit is higher compared to that of the dynamic displacement stiffness of the RMB unit.

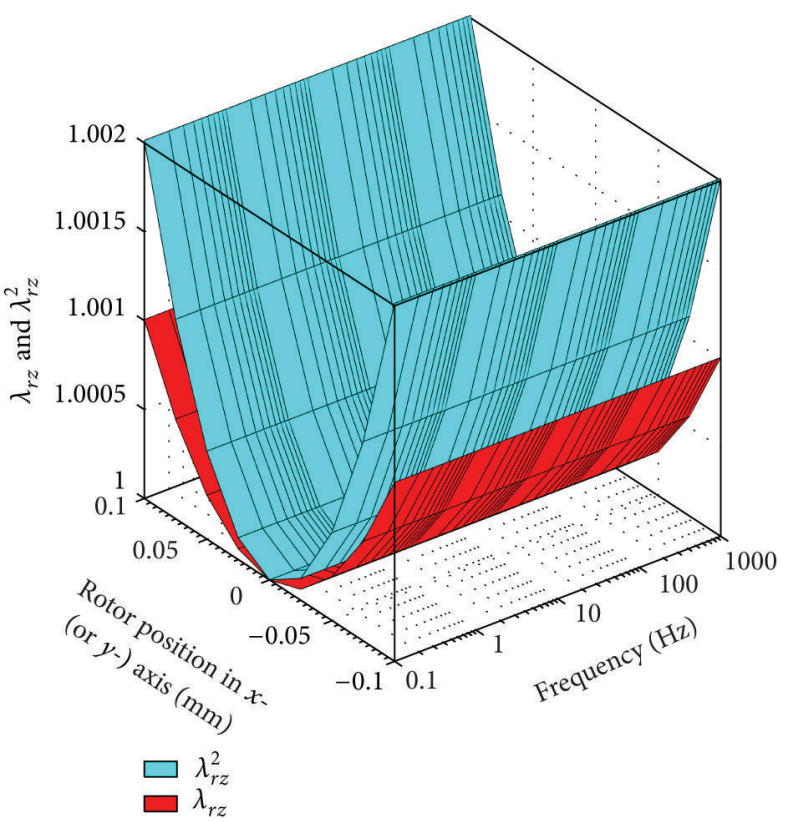

FIGURE 13: The coefficients $\lambda_{r z}$ and $\lambda_{r z}^{2}$.

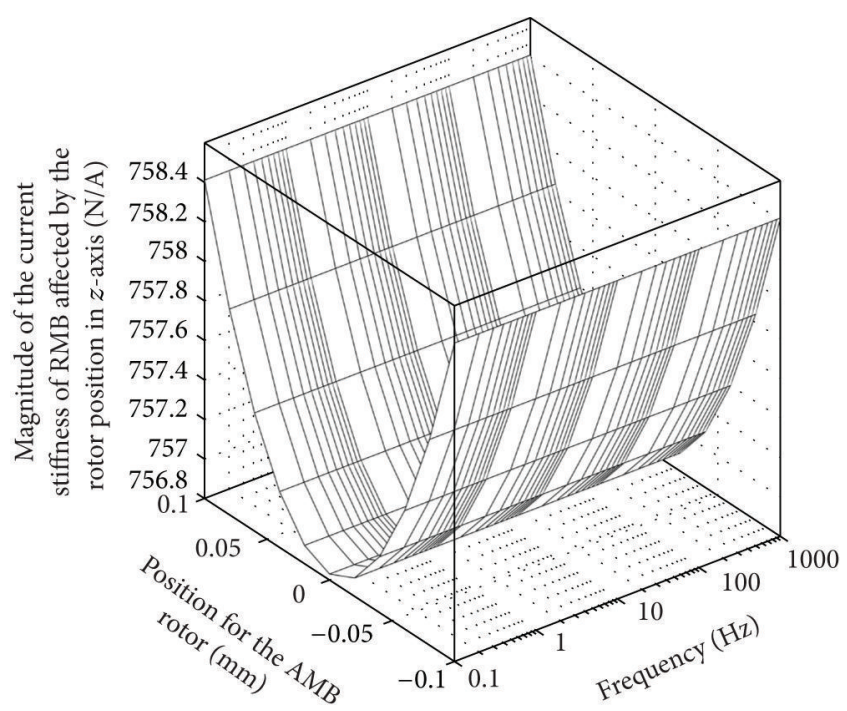

FIgURE 14: The magnitude of the dynamic current stiffness of the RMB unit versus varying frequency of the control current of the $\mathrm{RMB}$ unit and the rotor position in $z$-axis.

The magnitude of the dynamic current stiffness of the $A M B$ unit versus varying frequency of the control current in $\mathrm{AMB}$ unit and the rotor position of RMB unit in $x$-axis (or $y$-axis) is shown in Figure 11. And the magnitude of the dynamic displacement stiffness of the AMB unit versus varying frequency of the rotor position of the AMB unit in $z$-axis and the rotor position of RMB unit in $x$-axis is shown in Figure 12. It is obvious that the dynamic current stiffness and the dynamic displacement stiffness of the AMB unit are determined by the varying frequency of the control current in the AMB unit or the rotor position in $z$-axis rather than 


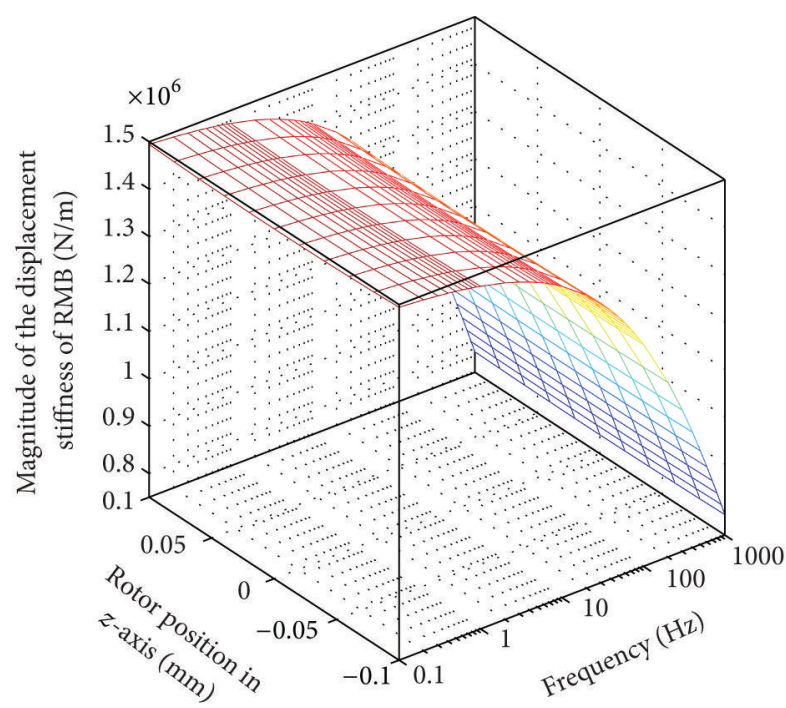

FIGURE 15: The magnitude of the dynamic displacement stiffness of the RMB versus varying frequency of the rotor position in $x$-axis and the rotor position of the AMB unit in $z$-axis.

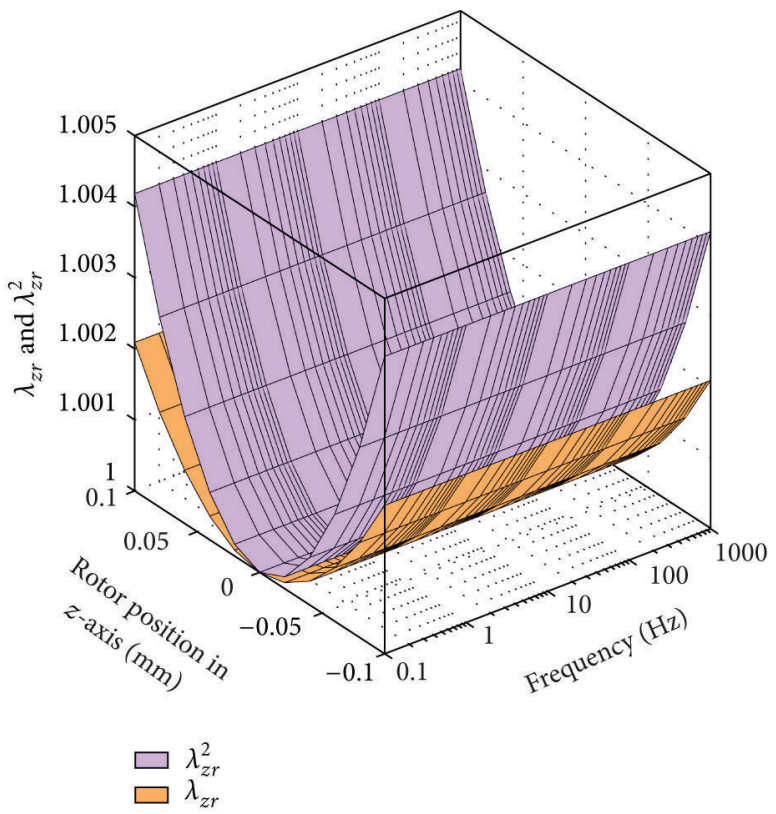

FIgURE 16: The coefficients $\lambda_{z r}$ and $\lambda_{z r}^{2}$.

the rotor position of the RMB unit in $x$-axis (or $y$-axis). The reason is the coefficients (shown in Figure 13) which are little affected by the rotor position in $x$-axis (or $y$-axis) direction.

The magnitude of the dynamic current stiffness of the RMB unit versus varying frequency of the control current in RMB unit and the rotor position in $z$-axis is shown in Figure 14. And the magnitude of the dynamic displacement stiffness of the RMB unit versus varying frequency of the rotor position in $x$-axis (or $y$-axis) and the rotor position in $z$-axis is shown in Figure 15. It is obvious that the dynamic current stiffness and the dynamic displacement stiffness of the RMB unit are determined by the varying frequency of the control current in the RMB unit or the rotor position in $x$ axis (or $y$-axis) rather than the rotor position of the AMB unit in $z$-axis. The reason is the coefficients (shown in Figure 16) which are little variation affected by the rotor position in $z$ axis.

\section{Conclusion}

The CRAMB with permanent magnet creating bias flux can reduce the size, cost, mass, and save energy of the magnetic bearing system $[6,7,12,16,17]$. The structure and its simplified dynamic stiffness models of a novel CRAMB with permanent magnet bias are presented when considering the eddy-current effect in this paper. And the dynamic crosscoupling models between axial and radial bearing units are also given using the method of equivalent magnetic circuit including eddy-current effect. An example is given and the analytical results show that the eddy-current effects have a fundamental impact on the dynamic stiffness of the CRAMB, but the dynamic current stiffness of the RMB unit is approximately equal to its static current stiffness. The bandwidths of the dynamic current stiffness of the $A M B$ unit and the dynamic displacement stiffness of the CRAMB are affected by the time-varying control currents or air gap respectively. The rotor position varying in $x$-axis (or $y$-axis) has little influence on the dynamic current stiffness and the dynamic displacement stiffness of the AMB unit due to the few coupling coefficients. And the rotor position varying in $z$-axis also has little influence on the dynamic current stiffness and the dynamic displacement stiffness of the RMB unit due to the little coupling coefficients. The described method can simulate the dynamic behavior of the CRAMB with permanent magnet.

\section{Conflict of Interests}

The authors declare that there is no conflict of interests regarding the publication of the paper.

\section{Acknowledgments}

This work was supported in part by the Aviation Science Fund of China under Grant 2012ZB51019 and by the Cultivation and Development Project of Science and Technology Innovation Base of Beijing under Grant Z131104002813105.

\section{References}

[1] J. Fang and Y. Ren, "High-precision control for a single-gimbal magnetically suspended control moment gyro based on inverse system method," IEEE Transactions on Industrial Electronics, vol. 58, no. 9, pp. 4331-4342, 2011.

[2] Z. Yang, L. Zhao, and H. Zhao, "Global linearization and microsynthesis for high-speed grinding spindle with active magnetic bearings," IEEE Transactions on Magnetics, vol. 38, no. 1, pp. 250-256, 2002.

[3] K. Hijikata, S. Kobayashi, M. Takemoto, Y. Tanaka, A. Chiba, and T. Fukao, "Basic characteristics of an active thrust magnetic 
bearing with a cylindrical rotor core," IEEE Transactions on Magnetics, vol. 44, no. 11, pp. 4167-4170, 2008.

[4] C. H. Park, S. K. Choi, and S. Y. Ham, "Design and control for hybrid magnetic thrust bearing for turbo refrigerant compressor," in Proceedings of the IEEE International Conference on Automation Science and Engineering (CASE '11), pp. 792-797, Trieste, Italy, August 2011.

[5] K.-C. Lee, Y.-H. Jeong, D.-H. Koo, and H. J. Ahn, "Development of a radial active magnetic bearing for high speed turbo-machinery motors," in Proceedings of the SICE-ICASE International Joint Conference, pp. 1543-1548, Busan, Republic of Korea, October 2006.

[6] P. Imoberdorf, C. Zwyssig, S. D. Round, and J. W. Kolar, "Combined radial-axial magnetic bearing for a $1 \mathrm{~kW}, 500,000 \mathrm{rpm}$ permanent magnet machine," in Proceedings of the 22nd Annual IEEE Applied Power Electronics Conference and Exposition (APEC '07), pp. 1434-1440, Anaheim, Calif, USA, March 2007.

[7] P. Imoberdorf, T. Nussbaumer, and J. W. Kolar, "Analysis of a combined radial-axial magnetic bearing for a high-speed drive system," in Proceedings of the 5th IET International Conference on Power Electronics, Machines and Drives (PEMD '10), pp. 1-6, Brighton, UK, April 2010.

[8] J. M. Watkins, G. Brown, and K. Blumenstock, "Control of integrated radial and axial magnetic bearings," in Proceedings of the 33rd Southeastern Symposium on System Theory, pp. 1-5, Athens, Ohio, USA, March 2001.

[9] K. A. Blumenstock and G. L. Brown, "Novel integrated radial and axial magnetic bearing," in Proceedings of the 7th International Symposium on Magnetic Bearings, pp. 467-472, Zurich, Switzerland, August 2000.

[10] H. Zhu, Z. Xie, and D. Zhu, "Principles and parameter design for AC-DC three-degree freedom hybrid magnetic bearings," Chinese Journal of Mechanical Engineering, vol. 19, no. 4, pp. 534-539, 2006.

[11] Z. Xie, H. Zhu, and Y. Sun, "Structure and control of AC-DC three-degree-of-freedom hybrid magnetic bearing," in Proceedings of the 11th International Conference on Electrical Machines and System, pp. 1801-1806, Wuhan, China, 2008.

[12] P. T. McMullen, C. S. Huynh, and R. J. Hayes, "Combination radial-axial magnetic bearing," in Proceedings of the 7th International Symposium on Magnetic Bearings, pp. 473-478, Zurich, Switzerland, August 2000.

[13] N. Wei, W. Qinghai, J. Defei, H. Xiaofeng, and Z. Tao, "Study on measuring and control system of AC radial-axial hybrid magnetic bearing used in wind energy generation system," in Proceedings of the 31st Chinese Control Conference (CCC '12), pp. 6847-6850, Hefei, China, July 2012.

[14] Y.-K. Sun and Z.-Y. Zhu, "Inverse-model identification and decoupling control based on least squares support vector machine for 3 degree-of-freedom hybrid magnetic bearing," Proceedings of the Chinese Society of Electrical Engineering, vol. 30, no. 15, pp. 112-117, 2010 (Chinese).

[15] F. Jiancheng, S. Jinji, L. Hu, and T. Jiqiang, "A novel 3-DOF axial hybrid magnetic bearing," IEEE Transactions on Magnetics, vol. 46, no. 12, pp. 4034-4045, 2010.

[16] K. Tsuchida, M. Takemoto, and S. Ogasawara, "A novel structure of a 3-axis active control type magnetic bearing with a cylindrical rotor," in Proceedings of the International Conference on Electrical Machines and Systems (ICEMS '10), pp. 1695-1700, Incheon, Republic of Korea, October 2010.

[17] U. J. Na, "Design and analysis of a new permanent magnet biased integrated radial-axial magnetic bearing," International
Journal of Precision Engineering and Manufacturing, vol. 13, no. 1, pp. 133-136, 2012.

[18] L. Huang, G. Zhao, H. Nian, and Y. He, "Modeling and design of permanent magnet biased radial-axial magnetic bearing by extended circuit theory," in Proceedings of the International Conference on Electrical Machines and Systems (ICEMS '07), pp. 1502-1507, Seoul, Republic of Korea, October 2007.

[19] S. Fukata, Y. Kouya, T. Shimomachi, Y. Mizumachi, and M. Kuga, "Dynamics of active magnetic thrust bearings," JSME International Journal. Series III, vol. 34, no. 3, pp. 404-410, 1991.

[20] J. J. Feeley, "A simple dynamic model for eddy currents in a magnetic actuator," IEEE Transactions on Magnetics, vol. 32, no. 2, pp. 453-458, 1996.

[21] L. Kucera and M. Ahrens, "A model for axial magnetic bearings including eddy currents," in Proceedings of the 3rd International Symposium on Magnetic Suspension Technology, Tallahassee, Fla, USA, December 1995.

[22] L. Zhu, C. R. Knospe, and E. H. Maslen, "Frequency domain modeling of non-laminated cylindrical magnetic actuators," in Proceedings of the 9th International Symposium on Magnetic Bearings, Lexington, Ky, USA, August 2004.

[23] L. Zhu, C. R. Knospe, and E. H. Maslen, "Analytic model for a nonlaminated cylindrical magnetic actuator including eddy currents," IEEE Transactions on Magnetics, vol. 41, no. 4, pp. 1248-1258, 2005.

[24] L. Zhu and C. R. Knospe, "Modeling of nonlaminated electromagnetic suspension systems," IEEE/ASME Transactions on Mechatronics, vol. 15, no. 1, pp. 59-69, 2010.

[25] Y. Sun, Active magnetic bearing: eddy current loss, nonlinear vibration and unbalance compensation [Ph.D. thesis], Xian Jiaotong University, Xi'an, China, 2001 (Chinese).

[26] J. R. Brauer, J. J. Ruehl, and F. Hirtenfelder, "Coupled nonlinear electromagnetic and structural finite element analysis of an actuator excited by an electric circuit," IEEE Transactions on Magnetics, vol. 31, no. 3, pp. 1861-1864, 1995.

[27] J. R. Brauer and Q. M. Chen, "Alternative dynamic electromechanical models of magnetic actuators containing eddy currents," IEEE Transactions on Magnetics, vol. 36, no. 4, pp. 1333-1336, 2000.

[28] Y. Kawase, T. Yamaguchi, K. Iwashita, T. Kobayashi, and K. Suzuki, "3-D finite element analysis of dynamic characteristics of electromagnet with permanent magnets," IEEE Transactions on Magnetics, vol. 42, no. 4, pp. 1339-1342, 2006.

[29] Y. Tian, Y. Sun, and L. Yu, "Modeling of Switching Ripple Currents (SRCs) for magnetic bearings including eddy current effects," International Journal of Applied Electromagnetics and Mechanics, vol. 33, no. 1-2, pp. 791-799, 2010.

[30] Y. Sun, Y.-S. Ho, and L. Yu, "Dynamic stiffnesses of active magnetic thrust bearing including eddy-current effects," IEEE Transactions on Magnetics, vol. 45, no. 1, pp. 139-149, 2009.

[31] B. Han, S. Zheng, and X. Hu, "Dynamic factor models of a thrust magnetic bearing with permanent magnet bias and subsidiary air gap," IEEE Transactions on Magnetics, vol. 49, no. 3, pp. 12211230, 2013.

[32] K. Muramatsu, T. Shimizu, A. Kameari et al., "Analysis of eddy currents in surface layer of laminated core in magnetic bearing system using leaf edge elements," IEEE Transactions on Magnetics, vol. 42, no. 4, pp. 883-886, 2006.

[33] H.-Y. Kim and C.-W. Lee, "Analysis of eddy-current loss for design of small active magnetic bearings with solid core and rotor," IEEE Transactions on Magnetics, vol. 40, no. 5, pp. 3293$3301,2004$. 
[34] P. E. Allaire, R. L. Fittro, E. H. Maslen, and W. C. Wakefield, "Eddycurrents, magnetic flux and force in solid magnetic thrust bearings," in Proceedings of the 4th International Symposium on Magnetic Bearings, pp. 157-163, Zurich, Switzerland, August 1994.

[35] R. T. DeWeese, A. B. Palazzolo, M. Chinta, and A. Kascak, "Magnetic thrust bearing concepts: tests and analyses," Journal of Intelligent Material Systems and Structures, vol. 9, no. 2, pp. 81-85, 1998.

[36] C. R. Knospe and L. Zhu, "Performance limitations of nonlaminated magnetic suspension systems," IEEE Transactions on Control Systems Technology, vol. 19, no. 2, pp. 327-336, 2011. 


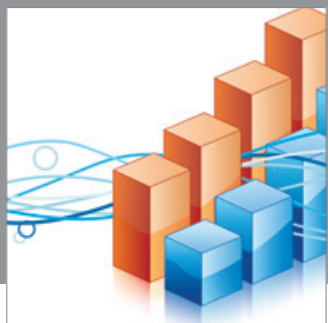

Advances in

Operations Research

mansans

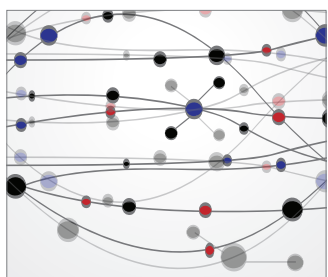

The Scientific World Journal
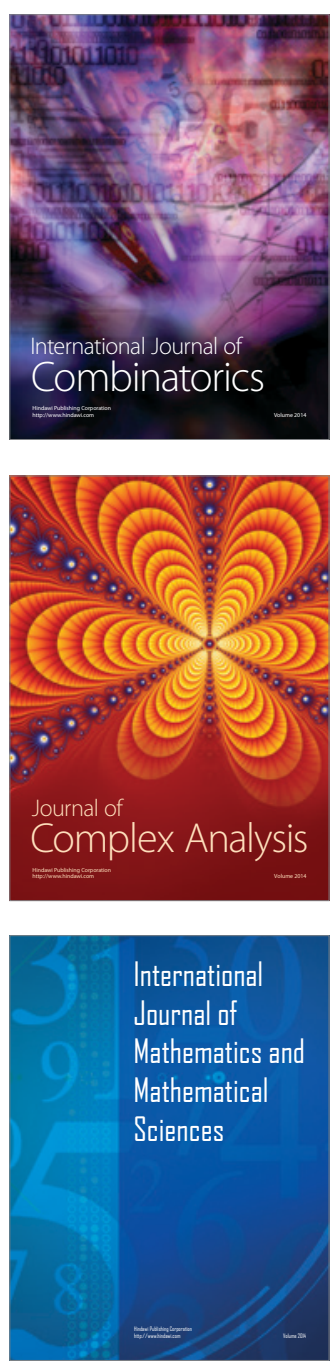
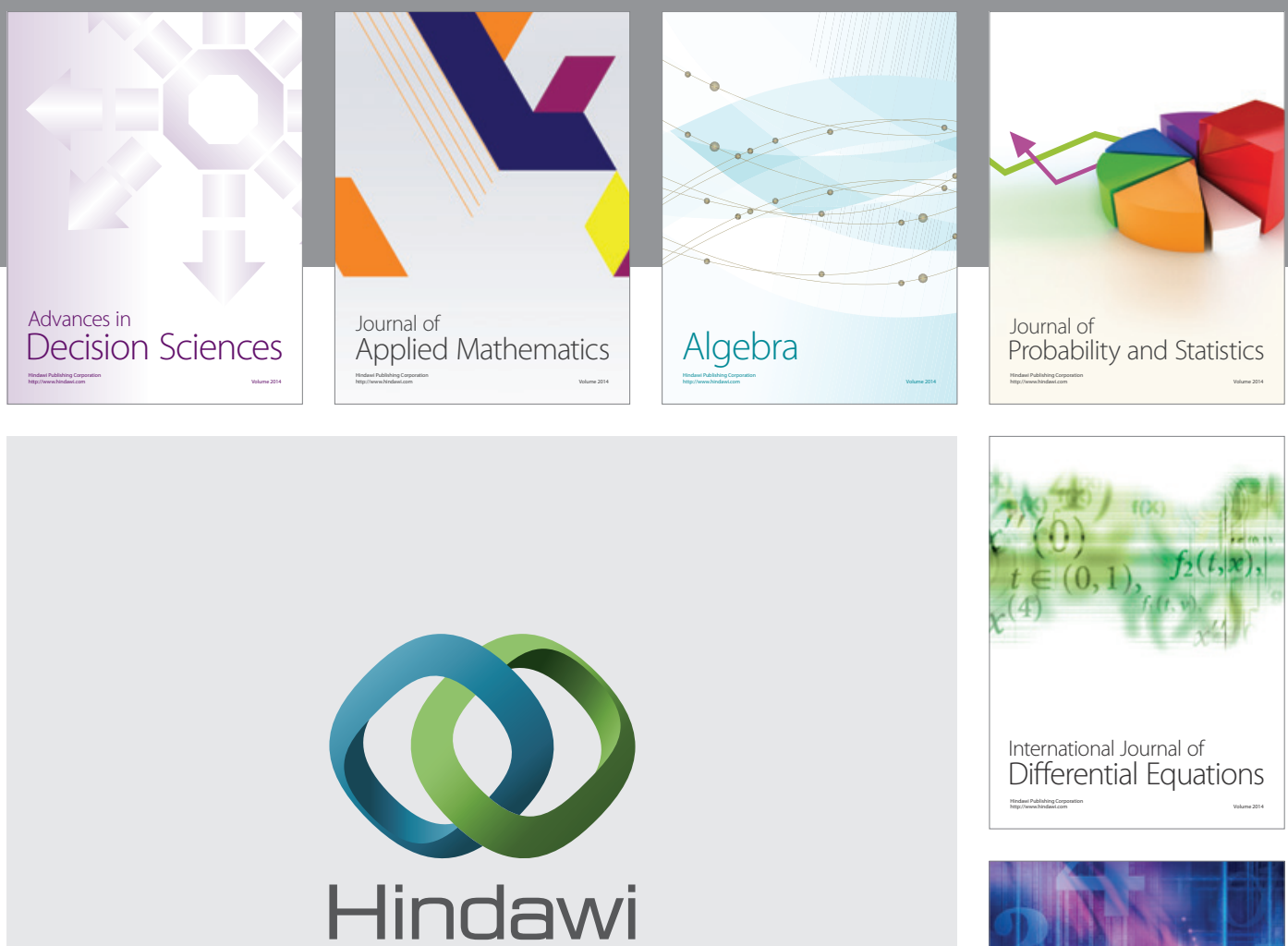

Submit your manuscripts at http://www.hindawi.com
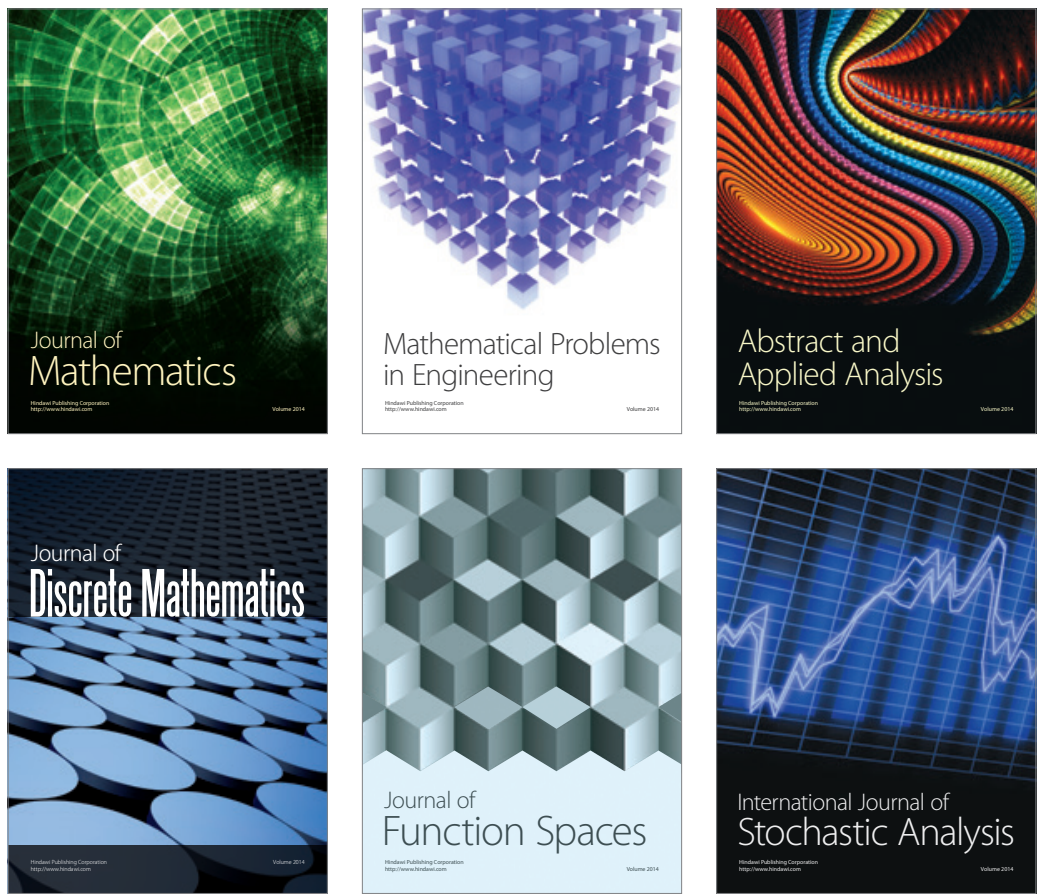

Journal of

Function Spaces

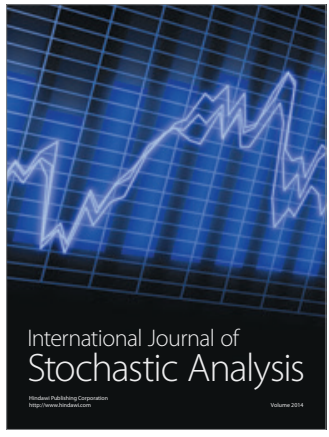

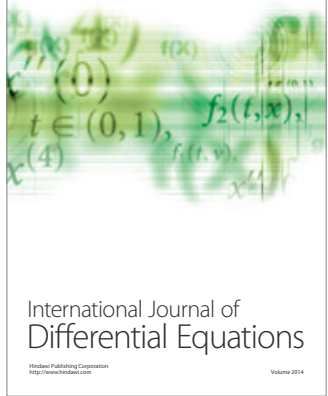
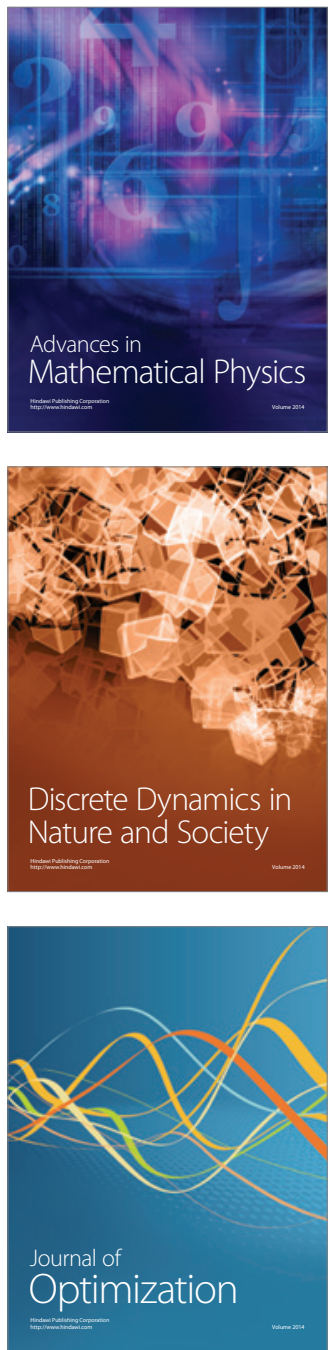